Article

\title{
Spatial Modeling of Urban Vegetation and Land Surface Temperature: A Case Study of Beijing
}

\section{Chudong Huang ${ }^{1}$ and Xinyue Ye ${ }^{2, *}$}

1 College of Civil Engineering and Architecture, Zhejiang University of Technology, No. 18 Chaowang Rd., Hangzhou 210014, China; E-Mail: cdhuang@zjut.edu.cn

2 Department of Geography, Kent State University, Kent, OH 44242, USA

* Author to whom correspondence should be addressed; E-Mail: xye5@kent.edu; Tel.: +1-419-494-7825; Fax: +1-330-672-4034.

Academic Editor: Marc A. Rosen

Received: 27 April 2015 / Accepted: 10 July 2015 / Published: 17 July 2015

\begin{abstract}
The coupling relationship between urban vegetation and land surface temperature (LST) has been heatedly debated in a variety of environmental studies. This paper studies the urban vegetation information and LST by utilizing a series of remote sensing imagery covering the period from 1990 to 2007 . Their coupling relationship is analyzed, in order to provide the basis for ecological planning and environment protection. The results show that the normalized difference vegetation index (NDVI), urban vegetation abundance (UVA) and urban forest abundance (UFA) are negatively correlated with LST, which means that both urban vegetation and urban forest are capable in decreasing LST. The apparent influence of urban vegetation and urban forest on LST varies with the spatial resolution of the imagery, and peaks at the resolutions ranging from $90 \mathrm{~m}$ to $120 \mathrm{~m}$.
\end{abstract}

Keywords: urban vegetation abundance; urban forest abundance; land surface temperature; Beijing

\section{Introduction}

Since 1978, China has been experiencing unprecedented market-oriented urban growth [1,2]. The 8\%-10\% annual gross domestic product (GDP) growth rate during the past 30 years has been accompanied with an urbanization rate growth from $18 \%$ in 1978 to $45 \%$ in 2007 [3]. One of the 
ecological consequences of dramatic urban growth and land use conversion is the significant decrease of urban vegetation and increase of the land surface temperature (LST) in the summer [4-6].

Both urban vegetation and urban land surface temperature are vital to maintaining public health and urban suitability in densely populated Chinese cities [7]. The coupling relationship between urban vegetation and higher atmospheric/surface temperatures in urbanized areas is therefore of great interest to a variety of urban planners and environmental scientists [8-12]. Extensive research has been conducted by deriving LST through moderate resolution imageries such as Thematic Mapper (TM), Enhanced Thematic Mapper Plus (ETM+), and Advanced Spaceborne Thermal Emission and Reflection Radiometer (ASTER). Normalized difference vegetation index (NDVI) is the most widely used vegetation index and has contributed to global climate, ecosystem, and agricultural studies [13,14]. For instance, Liu et al. [15] constructed NDVI time series (1982-2009) from the spectrum of three kinds of satellites, and to study the relationship among NDVI, climate factors and land cover changes. As a result, NDVI is mentioned in much of the remote sensing analysis between vegetation information and land surface temperature $[16,17]$. In addition, scholars have widely investigated the empirical relationships between LST and various biophysical or socio-economic measurements [6,18].

The research on urban vegetation and LST has been supported with growing availability of higher spatial and temporal resolution datasets and improved methods for geospatial analysis, along with debates over the trends and underlying forces of urban heat island effect [3]. However, much of the existing studies analyzing the relationship between NDVI and the Urban Heat Island (UHI) effect are based on brightness temperature or air temperature, rather than measurement of real land surface temperature [19-21]. Besides, in spite of these significant contributions, the study on the relationship between LST and vegetation information based on a time-series of remote sensing imagery is limited.

Urban forests, small enclaves of ecosystems featured with biological diversity in the artificial urban landscape, are considered as a specific part of vegetation in mitigating UHI [22]. Dramatic urban sprawl and urban growth have threatened such green space [23-25]. As urban forest provides much more environmental, ecological services than grassland or shrubs covering equivalent areas, such as air pollution removal, carbon storage, the urban forest has been analyzed as a specific part of urban vegetation [26-29]. The analysis of the relationship of urban forest and land surface temperature comparing that between NDVI or overall urban vegetation would be another key material for making decisions on mitigating UHI.

Beijing, the capital of China, has witnessed significant urban growth since the reforms that started in 1978, but it has been suffering from a growing assortment of environmental problems. These include severe air pollution, water shortages and traffic congestion. Beijing is noted for a poor climate throughout much of the year, with cold dry winters, spring periods of severe dust storms and hot summers. These climatic conditions are exacerbated by loss of vegetation, the urban heat island and air pollution and make life for the over 20 million inhabitants unpleasant and often unhealthy particularly in relation to respiratory ailments. The extent of the urbanized area of Beijing has expanded from approximately 269 square kilometers in 1975 to approximately 901 square kilometers in the 32 years up to 2007 and that rate has been continuing in the years since then. In this paper, the urban vegetation and LST are monitored and analyzed utilizing a time-series of remote sensed imagery dating from 1990 to 2007. Classification and regression tree (CART) models are generated and applied to estimate forest abundance, vegetation abundance and real LST. The coupling relationship between vegetation and LST 
are studied accordingly. The data were resampled at different spatial resolutions, similar as the downscaling of land surface temperature method of Ha et al. [30], so as to study the effect of scale on the coupling relationship. The analysis seeks to provide a basis for decision making to improve urban planning and environmental protection in Beijing and by extension in other urbanizing regions.

\section{Data, Study Site and Methods}

\subsection{Data and Study Site}

Beijing lies on the north tip of the North China Plain, with the geographic spread over the area between $39.5^{\circ}$ to $41.1^{\circ}$ North Latitude, and $115.4^{\circ}-117.5^{\circ}$ East Longitude (Figure 1a). The city is near the meeting point of the Xishan and Yanshan mountain ranges. The main part of the city lies on flat land with elevations of $20 \mathrm{~m}$ to $60 \mathrm{~m}$ above sea level that opens to the east and south. The municipality's outlying districts and counties extend into the mountains that surround the city from the southwest to the northeast. The highest peaks are over $2000 \mathrm{~m}$ high. These mountains contribute to trapping smog that gives Beijing the distinction of having some of the planets worst air pollution as the situation is made worse by the urban heat island effect and by loss of urban vegetation. The urban heat island effect intensifies the urban temperature in the hot, humid and smoggy summers, while urban vegetation is efficient in decreasing UHI effect. Figure $1 \mathrm{~b}$ is a true color image of the study area from a Landsat ETM+ image acquired in the year 2000 .

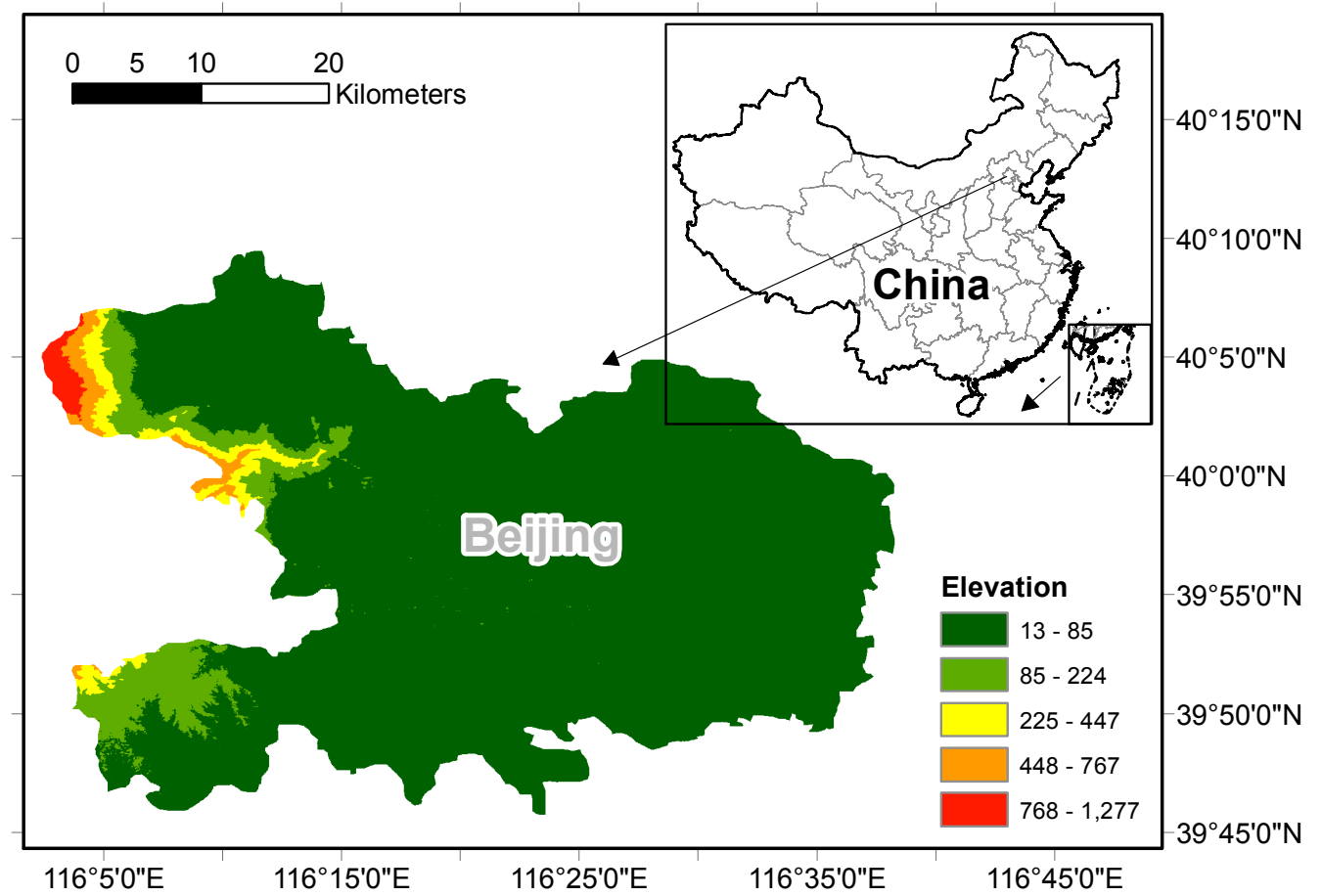

(a) location and elevation

Figure 1. Cont. 


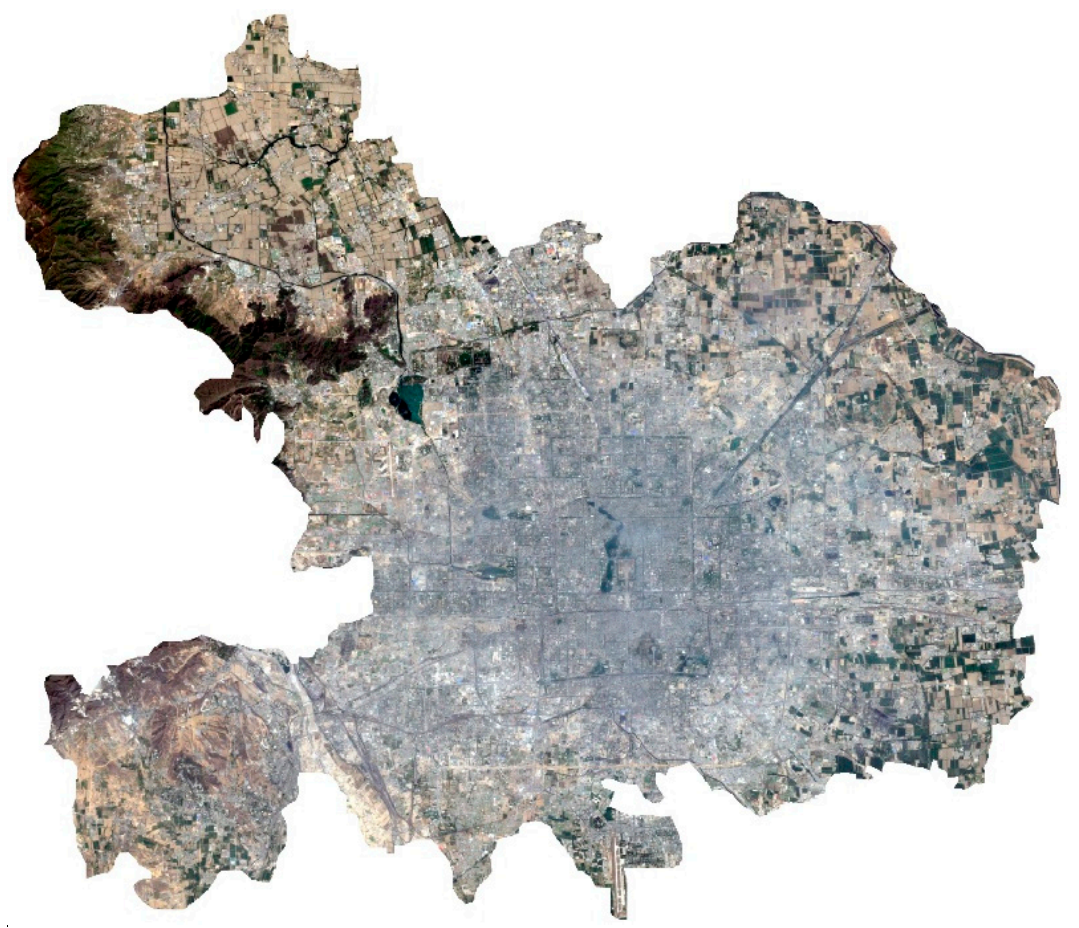

(b) true color image (Landsat ETM+, 30 April 2000)

Figure 1. The location, elevation (a) and a true color image (b) of the central part of Beijing City.

In the analysis, a time-series of remote sensing imagery (Table 1) is utilized to estimate the vegetation information and LST. The vegetation information consists of forest abundance, vegetation abundance and NDVI. Urban forest is also included. These images were acquired on the sunny days. As the precipitation before acquisition date would affect LST, the precipitation data within $24 \mathrm{~h}$ until 8:00 PM of the day before the acquisition date is also listed in Table 1.

Table 1. Time-series of remote sensing imagery and the precipitation before acquisition date.

\begin{tabular}{cccc}
\hline & Data Type & Acquisition date & Precipitation before acquisition date (mm) * \\
\hline 1 & Landsat TM & 13 May 1990 & 1 \\
2 & Landsat TM & 7 September 1992 & $0(159$ the day before $)$ \\
3 & Landsat TM & 8 May 1994 & 0 \\
4 & Landsat TM & 21 September 1997 & 0 \\
5 & Landsat TM & 6 May 1999 & 0 \\
6 & Landsat ETM+ & 1 July 1999 & 0 \\
7 & Landsat ETM+ & 30 April 2000 & 13 \\
8 & Landsat ETM+ & 19 May 2001 & 0 \\
9 & Terra ASTER & 4 June 2001 & 0 \\
10 & Terra ASTER & 12 June 2004 & 0 \\
11 & Terra ASTER & 22 April 2006 & 0 \\
12 & Terra ASTER & 8 August 2007 & 68 \\
\hline
\end{tabular}

* The precipitation data is provided by China Meteorological Administration. 


\subsection{Estimation of Vegetation Cover}

\subsubsection{NDVI}

NDVI is calculated using the red and near infrared band of the ASTER by using Equation (1) as follows:

$$
N D V I=\frac{\rho_{N I R}-\rho_{R}}{\rho_{N I R}+\rho_{R}}
$$

where $\rho_{\text {NIR }}$ and $\rho_{R}$ are the reflectivity of near infrared and red band of the ASTER sensor respectively.

\subsubsection{Vegetation Abundance}

Vegetation abundance in each pixel of the area of Beijing covered by the images is computed using a Dimidiate Pixel Model based on NDVI [31], as shown in Equation (2) below:

$$
V_{g}=\frac{N D V I_{\text {pixel }}-N D V I_{0}}{N D V I_{\infty}-N D V I_{0}}
$$

where $N D V I_{\text {pixel }}$ is the NDVI value in each pixel. $N D V I_{0}$ and $N D V I_{\infty}$ are the NDVI values where the pixel contain bare soil and full vegetation cover respectively. A frequency accumulation method is employed to estimate the value of $N D V I_{0}$ and $N D V I_{\infty}$, where frequency accumulations are $5 \%$ and $95 \%$, respectively. Figure 2 shows the vegetation abundance derived from Landsat enhanced thematic mapper (ETM+) imagery for 1999.

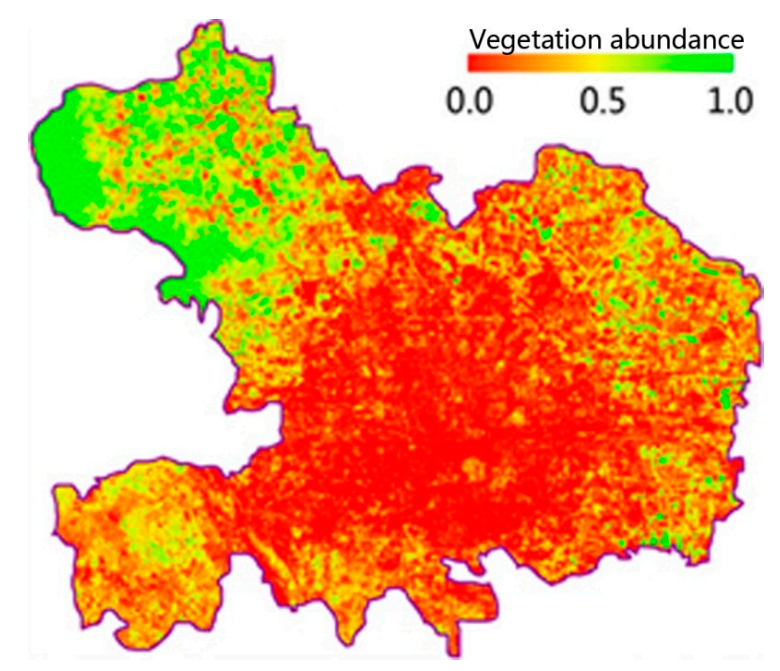

Figure 2. An example map of vegetation abundance (Landsat ETM+, 1 July 1999).

\subsubsection{Forest Abundance}

Compared to vegetation abundance, forest abundance is computed using a different method. The method consists of three steps (Figure 3). Classification and regression tree techniques are applied in the sub-pixel classification of the remote sensing imagery. First, training areas are chosen, and the imagery of various areas with varying levels of forest cover are retrieved from the use of Quickbird images, airborne remote sensing images and from field surveys (ground truth). Then, a raster based geographic 
information system (GIS) data layer of forest abundance (i.e., percentage of forest within each pixel) is produced within the $15 \mathrm{~m} \times 15 \mathrm{~m}$ area of the corresponding ASTER data layer and $30 \mathrm{~m} \times 30 \mathrm{~m}$ pixel area for Landsat TM data. The forest abundance data in each pixel, as well as Landsat TM/ETM+/ASTER spectrum and NDVI values, are stored in the GIS as model training data and used as accuracy assessment data. Secondly, the relationships between forest abundance and Landsat TM/ETM+/ASTER spectrum and NDVI are learned by the Cubist software, which is a tool from an Australian company RuleQuest Research for generating rule-based predictive models from data, and a suit of regression tree models for calculating forest abundance are thereby generated. The models are estimated and adjusted by use of the accuracy assessment data. Step 3: the forest abundance over the entire study area is calculated, utilizing the models and Landsat TM/ETM+/ASTER data. Figure 4 is an example map of forest abundance derived from Landsat TM imagery from 1999.

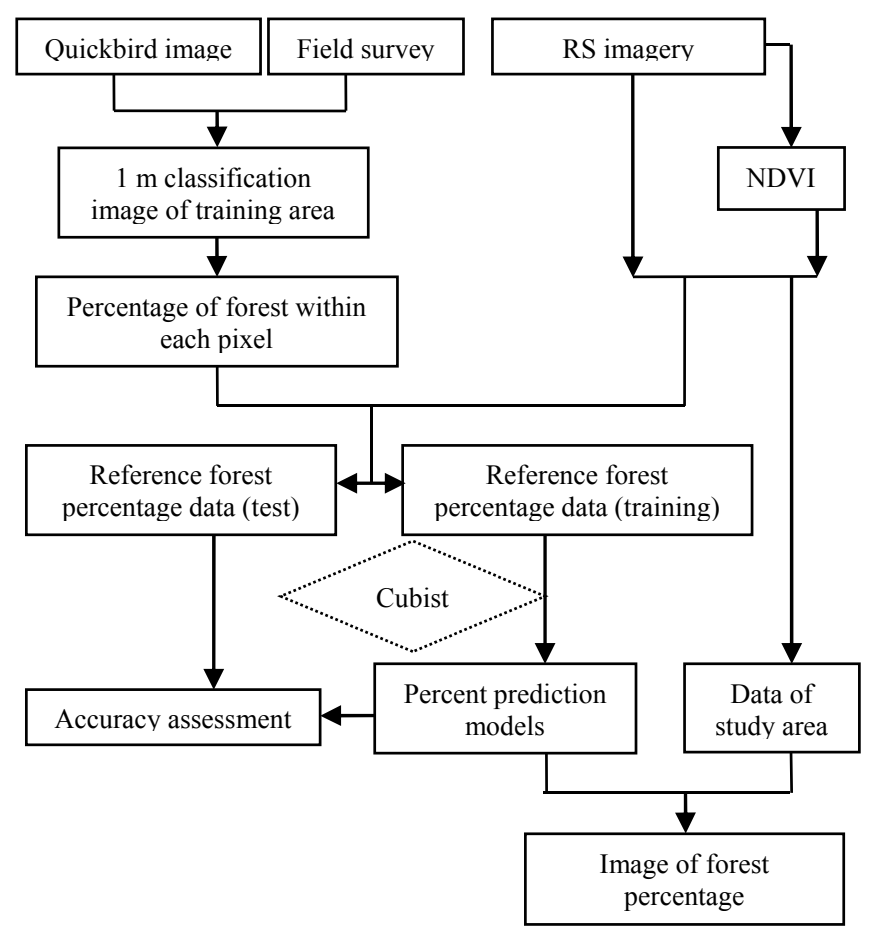

Figure 3. A flowchart of forest abundance retrieval.

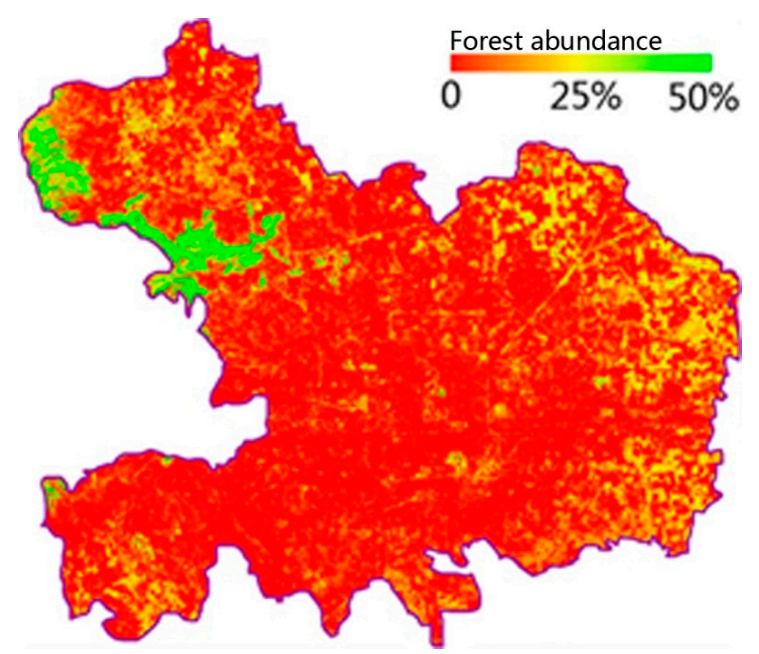

Figure 4. An example map of forest abundance (Landsat TM, 6 May 1999). 


\subsection{LST Retrieval}

Landsat TM/ETM+ and Terra ASTER images have many similarities. The processes of LST retrieval are concluded as shown in Figure 5. The LST calculation is generated based on land surface emissivity and land surface brightness temperature. The calculation of land surface brightness temperature based on use of these two types (Landsat TM, ASTER) of images is different, because Landsat TM images have only one thermal infrared (TIR) band, while ASTER images have four TIR bands; while step 1 and 3 for the two types of data are generally the same.

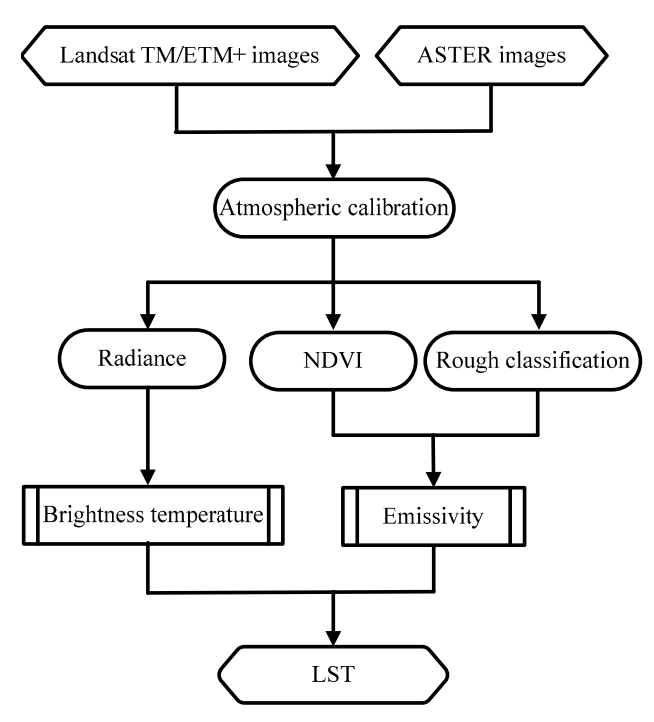

Figure 5. A flowchart of land surface temperature (LST) retrieval.

\subsubsection{Land Surface Emissivity Estimation}

Based on the method of Qin [32] and Sobrino [33], land surface emissivity is estimated as follows in Equations (3)-(5) below:

for NDVI $<0.05, \varepsilon=0.973$;

for NDVI $>0.7, \varepsilon=0.99$;

and for $0.05 \leq$ NDVI $\leq 0.7$.

$$
\begin{gathered}
\varepsilon=0.004 P_{v}+0.986 \\
P_{v}=\left(\frac{N D V I-N D V I_{s}}{N D V I_{v}-N D V I_{s}}\right)^{2}
\end{gathered}
$$

where: $\varepsilon$ is the land surface emissivity; $N D V I$ is the normalized difference vegetation index of the pixel; $N D V I_{S}$ and $N D V I_{V}$ are respectively the $N D V I$ of bare soil and of vegetation, which are assigned values of 0.05 and 0.7 .

\subsubsection{LST Calculation from Landsat TM/ETM+ Imagery}

Since Landsat TM/ETM+ imagery has just one TIR band (band 6), only single-channel methods can be used to estimate LST [9]. Various methods have been proposed for retrieving LST from Landsat 
images, which do not require any atmospheric parameters or other auxiliary data. In this study, a generalized single-channel method [34] for Landsat data analysis is applied to calculate the LST. It requires two essential parameters for the estimation process: values for emissivity and transmittance. Generally, it requires the estimation of two principal parameters: one is the brightness temperature, the other is the emissivity. Both of them can be derived from Landsat TM/ETM data using this method. According to the generalized single channel method mentioned above, the following Equations (5)-(10) are utilized:

$$
\begin{gathered}
T_{s}=\gamma\left[\varepsilon^{-1}\left(\psi_{1} L_{\text {sensor }}+\psi_{2}\right)+\psi_{3}\right]+\delta \\
\gamma=\left\{\frac{c_{2} L_{\text {sensor }}}{T_{\text {sensor }}^{2}}\left[\frac{\lambda^{4}}{c_{1}} L_{\text {sensor }}+\lambda^{-1}\right]\right\}^{-1} \\
\delta=-\gamma L_{\text {sensor }}+T_{\text {sensor }} \\
\psi_{1}=0.14714 w^{2}-0.15583 w+1.1234 \\
\psi_{2}=-1.1836 w^{2}-0.37607 w-0.52894 \\
\psi_{3}=-0.04554 w^{2}+1.8719 w-0.39017
\end{gathered}
$$

where: $W$ is atmospheric moisture value acquired from the MODerate resolution atmospheric TRANsmission (MODTRAN) computer model; $\psi_{1}, \psi_{2}$ and $\psi_{3}$ are atmospheric parameters; $L_{\text {sensor }}$ is radiance at the sensor; $\lambda=11.457 \mu \mathrm{m}$ is the effective wavelength for Landsat TM/ETM+ images; $\varepsilon$ is the land surface emissivity; $c_{1}=1.19104 \times 10^{8} \mathrm{Wum}^{4} \mathrm{~m}^{-2} \mathrm{Sr}^{-1}, c_{2}=14387.7 \mu \mathrm{mK} ; T_{s}$, with units of degrees kelvin $(K)$, is the land surface temperature. Figure 6 is an example of a map of land surface temperature (LST in degrees Celsius ${ }^{\circ} \mathrm{C}$ ) derived from Landsat ETM+ imagery from 1999.

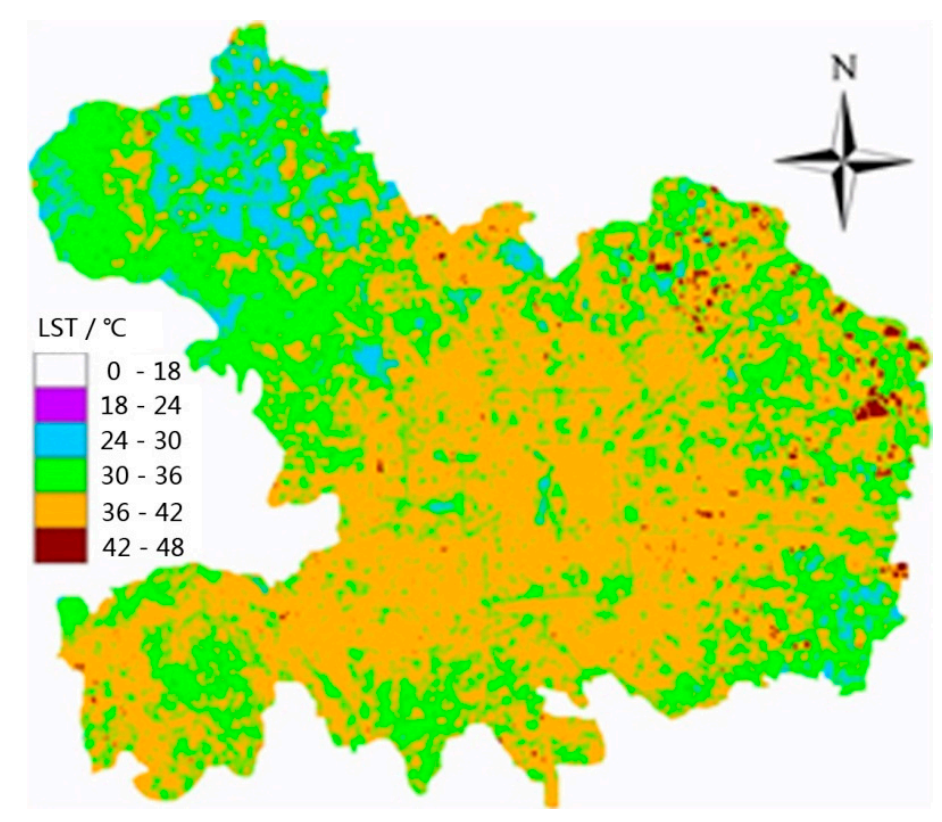

Figure 6. An example map of land surface temperature $\left(\mathrm{LST} /{ }^{\circ} \mathrm{C}\right)(\mathrm{Landsat} \mathrm{ETM}+, 1 \mathrm{July} 1999)$. 


\subsubsection{LST Calculation from Terra ASTER Images}

ASTER images, which contain five thermal infrared bands with $90 \mathrm{M}$ resolution, are more feasible to use to calculate the LST. However, there is less research on LST estimation using ASTER imagery than derivation of LST using Landsat imagery. In this analysis, a split-window algorithm [20] is used for the purpose of LST estimation. Bands 13 and 14 are used for the calculation. It also requires two essential parameters be derived for the estimation. They are emissivity and transmittance. The former is derived from the ASTER data, while the latter is calculated using Moderate resolution Imaging Spectroradiometer (MODIS) data acquired by the same satellite at the same time as the ASTER data.

Kaufman [35] proposed that Equations (11) and (12) can be used for this purpose:

$$
\begin{gathered}
\tau(19 / 2)=\rho(19) /\left[C_{1} \times \rho(2)+C_{2} \times \rho(5)\right] \\
{ }_{W}=\left(\frac{\alpha-\ln \tau}{\beta}\right)^{2}
\end{gathered}
$$

where: $\tau(19 / 2)$ is the atmosphere transparency of band 19 of the MODIS data; $\rho(2)$ and $\rho(5)$ are respectively the radiance of bands 2 and 5 in the MODIS data; $C_{1}=0.8, C_{2}=0.2, \alpha=0.02$, $\beta=0.651, W$ in $\mathrm{g} / \mathrm{cm}^{2}$ is the atmospheric moisture.

According to the split-window algorithm developed by Mao et al. [36], in 2006, Equation (13) can be employed:

$$
T_{s}=\frac{C_{14}\left(D_{13}+B_{13}\right)-C_{13}\left(D_{14}+B_{14}\right)}{C_{14} A_{13}-C_{13} A_{14}}
$$

where:

$$
\begin{aligned}
& A_{13}=0.145236 \times \varepsilon_{13} \times \tau_{13} \\
& B_{13}=0.145236 \times T_{13}+33.685 \times \varepsilon_{13} \times \tau_{13}-33.685 \\
& C_{13}=\left(1-\tau_{13}\right) \times\left[1+\left(1-\varepsilon_{13}\right) \times \tau_{13}\right] \times 0.145236 \\
& D_{13}=\left(1-\tau_{13}\right) \times\left[1+\left(1-\varepsilon_{13}\right) \times \tau_{13}\right] \times 33.685 \\
& A_{14}=0.13266 \times \varepsilon_{14} \times \tau_{14} \\
& B_{14}=0.13266 \times T_{14}+30.273 \times \varepsilon_{14} \times \tau_{14}-30.273 \\
& C_{14}=\left(1-\tau_{14}\right) \times\left[1+\left(1-\varepsilon_{14}\right) \times \tau_{14}\right] \times 0.13266 \\
& D_{14}=\left(1-\tau_{14}\right) \times\left[1+\left(1-\varepsilon_{14}\right) \times \tau_{14}\right] \times 30.273
\end{aligned}
$$

\subsection{Coupling Relationship Analysis}

The coupling relationship analysis consists of four parts. The first three are an analysis of the relationship between NDVI and LST, urban vegetation cover and LST and urban forest cover and LST; while the last one is the coupling relationship sensitivity to analysis under different resolutions of imagery.

Each of the first three analyses steps consists of two steps:

Step 1: draw a scatter plot of the vegetation information and LST to define the relationship. 
Step 2: divide each type of vegetation information into mini-intervals, e.g., 100 intervals for NDVI, and analyze the relationship between the original values of the LST estimates and vegetation cover estimates, as well as the means of the mini-intervals and the means of the corresponding LST estimates.

In the following analysis, Pearson's correlation coefficient is calculated to indicate the level of the correlation, which is defined by Equation (14) as:

$$
r=\frac{\sigma_{x y}{ }^{2}}{\sigma_{x} \sigma_{y}}=\frac{\sum(x-\bar{x})(y-\bar{y})}{\sqrt{\sum(x-\bar{x})^{2}} \cdot \sqrt{\sum(y-\bar{y})^{2}}}
$$

where $r$ is Pearson's correlation coefficient; $x, y$ are the variables, e.g., NDVI and LST; $x, \bar{y}$ are their mean values. The range of $r$ is $[-1,1]$ :

- $\quad r \in[-1,0): x, y$ are negative correlations, absolutely negative correlations if $r=-1$;

- $\quad r=0: x, y$ are absolutely not correlated;

- $\quad r \in(0,1]: x, y$ are in positively correlated, and absolutely positively correlated if $r=1$;

$R^{2}$ is calculated for the linear fits and quadratic fits, and is defined by Equation (15) as:

$$
R^{2}=\frac{\sum(Y-\bar{y})^{2}}{\sum(y-\bar{y})^{2}}
$$

where $Y$ is the predicted value of the linear fit or quadratic fit, $y$ and $\bar{y}$ are same as in Equation (14).

\section{Results and Discussion}

\subsection{NDVI and LST}

The scatter plot of NDVI and LST in each year is shown in Figure 7. It is an example derived from the Landsat ETM+ image from 1999. The range of NDVI is [-1, 1]. It is divided into 100 intervals. The mean value of NDVI in these intervals and the mean temperatures in corresponding areas are collected, i.e., "mean of intervals" in Figure 8, so that scatter plots of mean NDVI and LST for each set of intervals is portrayed. In Figure 8, this data is portrayed based on Landsat ETM+ data acquired in 2000.

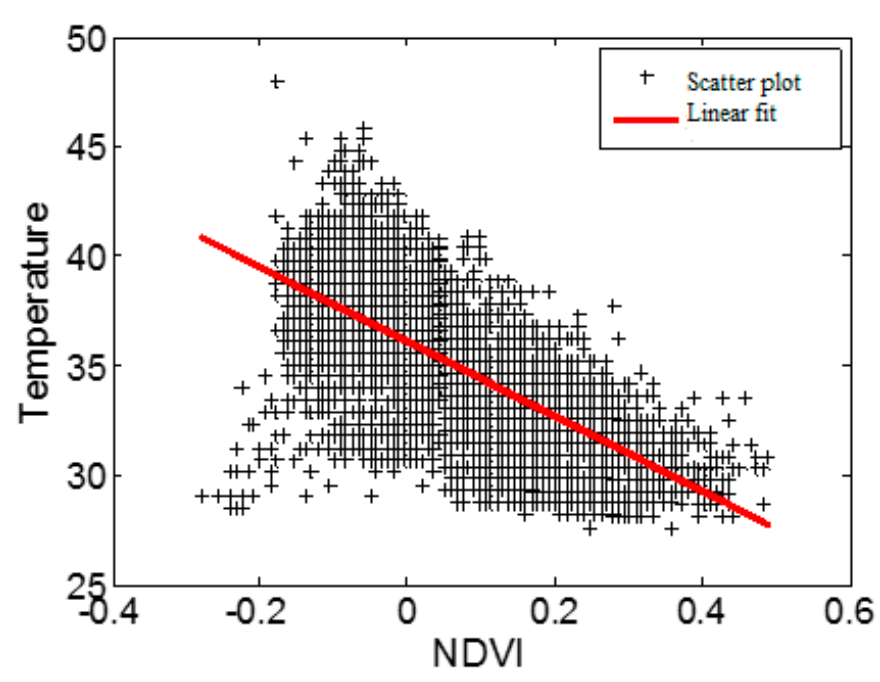

Figure 7. An example of scatter plot of NDVI-LST (Landsat ETM+, 1 July 1999). 


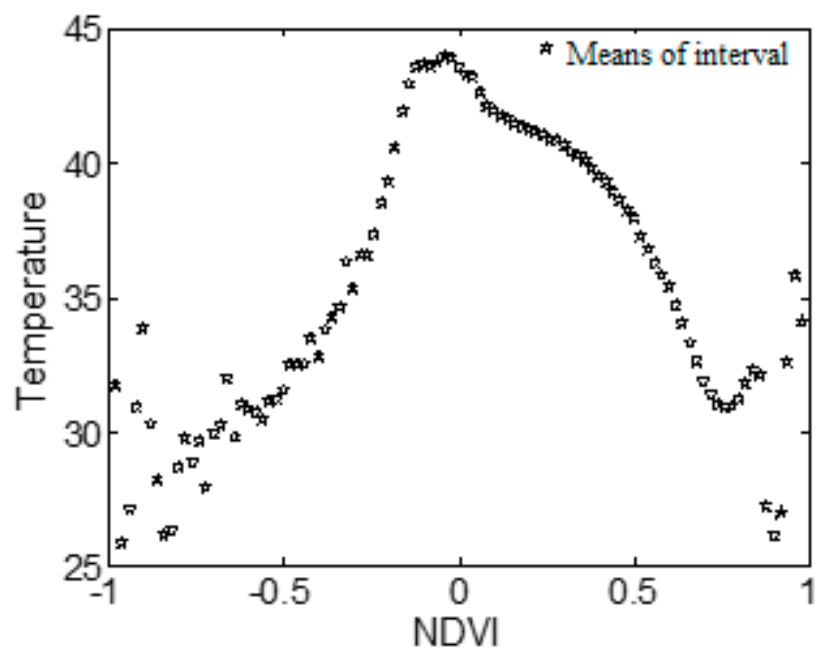

Figure 8. An example scatter plot of mean NDVI and LST of intervals (Landsat ETM+, 1 July 1999).

Based on the analysis portrayed in Figure 7 and Figure 8, the relation between NDVI and LST can be classified by three categories by threshold values defined as follows: Water is the least of the three categories defined by threshold values, the corresponding area where NDVI is in the range [-1, water] is generally a water body or an area covered by clouds [35]. Bare soil is the second category, it occurs where NDVI is around the threshold value associated with bare soil. NDVI and LST are generally in a positive relationship where NDVI is in this range [water, bare soil]. Vegetation cover is the third category defined by threshold values. Where NDVI is in the range (bare soil, vegetation cover), the corresponding areas are partly covered by vegetation. This range is the most relevant NDVI range for the analysis. In these areas, NDVI and LST have a significant negative correlation. The corresponding areas where NDVI is in the range [vegetation cover, 1], are generally fully covered by vegetation.

NDVI values are divided into four ranges, and then separately linearly fitted/quadratically fitted with the LST values. Six of all the twelve potential permutations of the relationship between the categories of NDVI and LST, are chosen for example and portrayed in Figure 9, covering three types of sensors and from the beginning to the end of the research period. The associated parameters are listed in Table 2 . In the range [ -1 , water), NDVI and LST are roughly in negative correlation. However, the corresponding area accounts for only a small percentage of the total area, and these areas are mostly not covered by vegetation. For Landsat TM in 1990, the coefficient of determination $R^{2}$ is 0.1253 , while it is 0.0016 for the Terra ASTER in 2007.

In the range of [water, bare soil], NDVI and LST are generally positively correlated. For Landsat TM in 1990 and Terra ASTER in 2007, the monomial coefficients of linear fit are 42.52 and 48.73 respectively, while the $R^{2}$ values are 0.42 and 0.08 respectively. In the range of (bare soil, vegetation cover), NDVI and LST are strongly negatively correlated. For the monomial coefficient of linear fit, which indicates the influence of increasing NDVI on decreasing LST, is generally in the range of $[-8,-24]$, while the mean value is -15.915 . For Landsat TM in 1990 and Terra ASTER in 2007, the monomial coefficients are -12.30 and -21.64 , respectively. The value varies with atmospheric conditions, soil moisture, climate, land cover and other conditions. The areas with the same NDVI are in different soil moisture, climatic and other conditions, so that the corresponding LST varies significantly. As a result, the $R^{2}$ values hardly reach 0.8 . Also in the range (bare soil, vegetation cover), 
the mean NDVI of the intervals and the corresponding LST are linearly fitted. The monomial coefficients approach the monomial coefficients of direct linear fit mentioned above (and shown in Table 2). However, the $R^{2}$ values are much greater, most them are greater than 0.9 .

In the range [vegetation cover, 1], the corresponding areas are mostly covered by vegetation [20]. In these areas, NDVI and LST are not in a stable relationship. For example, the fitting results from the Landsat TM imagery from 1990 is quite different from that derived from the same imagery by the same analysis methods for 1992. It is noticed that in the west of the study area, the elevation is higher than most of other parts. There is a famous hill (Xiangshan Park) that is a park covered with forest. In this area, the elevation is one of the significant elements that influences LST. While there was some urban growth over the intervening two years other factors such as soil moisture, climate, leaf area index and atmospheric moisture probably account for the differences. Consequently, it is evident that in this range, LST is mainly determined by elevation, Leaf Area Index (LAI), soil moisture, etc., other than by NDVI. The last two columns of Table 2 list the Pearson's correlation coefficient relationship between NDVI and LST, where the latter column calculates the case where NDVI is in the range (bare soil, vegetation cover). The results show that NDVI and LST are generally in a negative correlation, and in those areas covered by vegetation, NDVI and LST are more strongly negatively correlated (most of the Pearson's correlation coefficients are greater than 0.95 ).

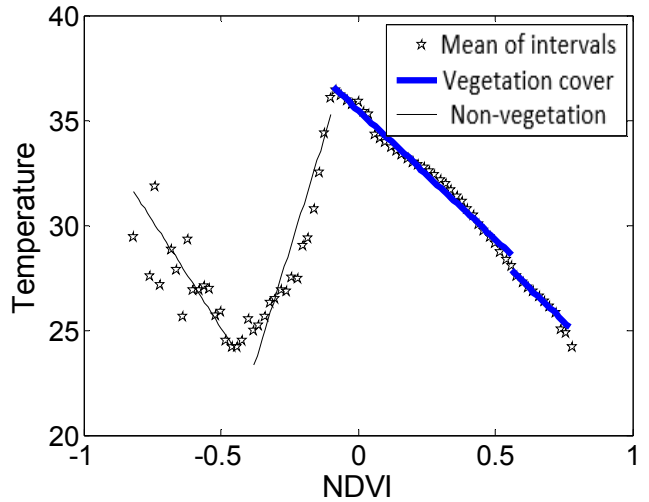

(a) Landsat TM, 13 May 1990

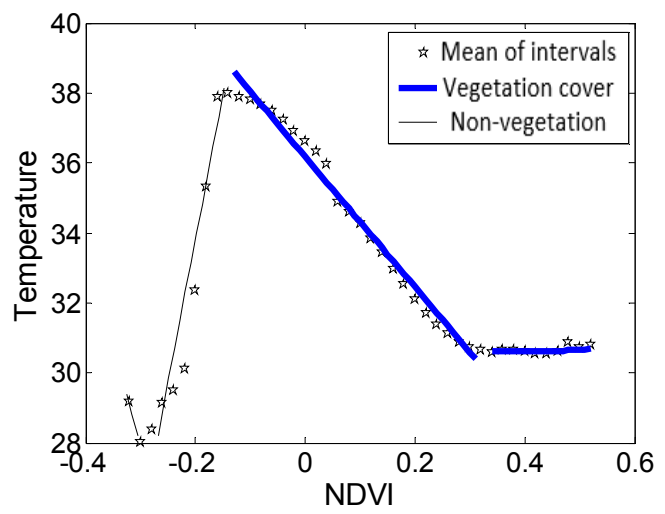

(c) Landsat ETM+, 1 July 1999

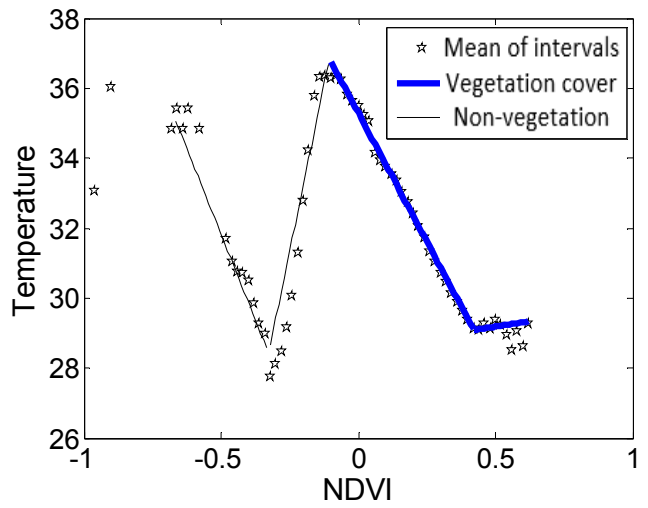

(b) Landsat TM, 8 May 1994

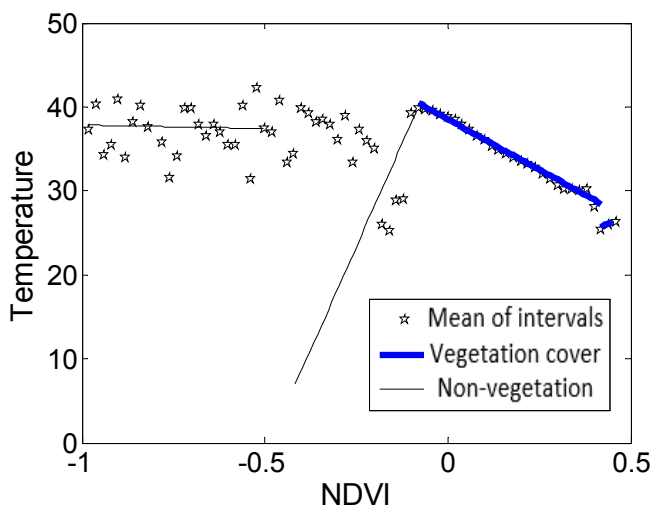

(d) Terra ASTER, 4 June 2001

Figure 9. Cont. 


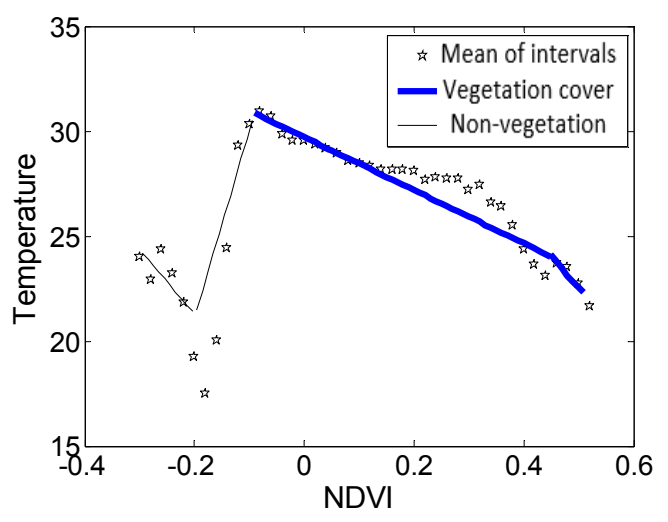

(e) Terra ASTER, 22 April 2006

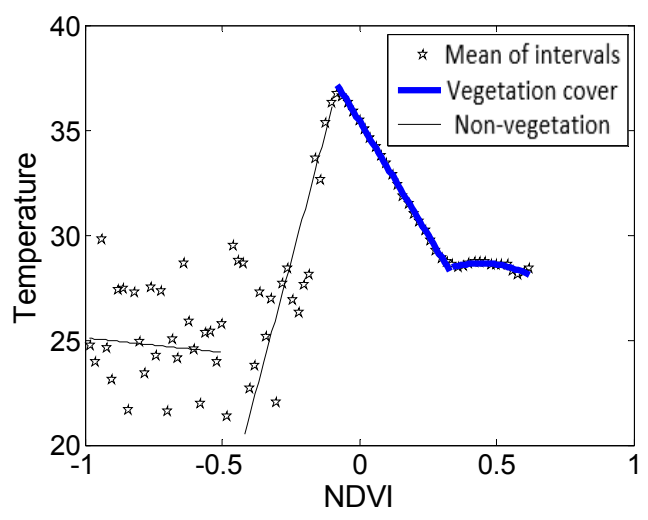

(f) Terra ASTER, 8 August 2007

Figure 9. Eamples of relation between NDVI and LST.

\subsection{Urban Vegetation Abundance and LST}

The scatter plot of urban vegetation abundance (UVA) and LST in each year is portrayed in Figure 10. It is based on an example derived from the Landsat ETM+ image from 1999. The range of UVA is [0, 100\%]. It is divided into 100 intervals. The mean values of UVA in these intervals and the mean LST in the corresponding areas are collected, i.e., "mean of intervals", so that scatter plots of the mean UVA-LST of the intervals are derived and portrayed in Figure 11. Six of twelve results are chosen covering three types of sensors and from the beginning to the end, but mostly different from those chosen in Figure 9. Based on these scatter plots shown in Figures 10 and 11, the relationship between UVA and LST is evidently a negative correlation most of the time.

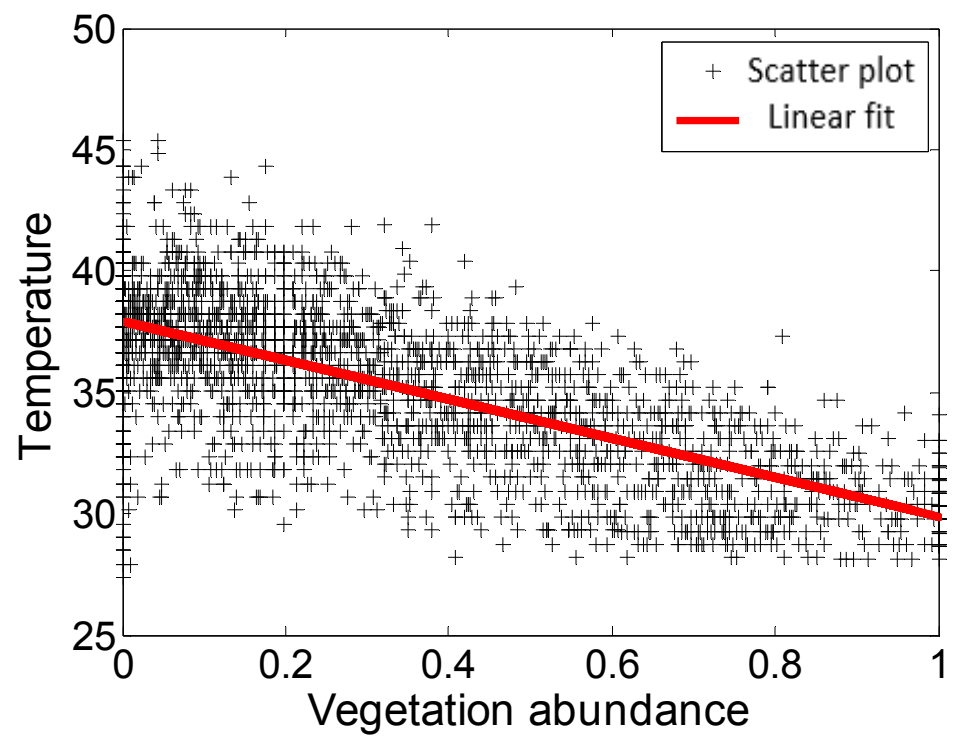

Figure 10. An example of scatter plot of UVA-LST (Landsat ETM+, 1 July 1999). 


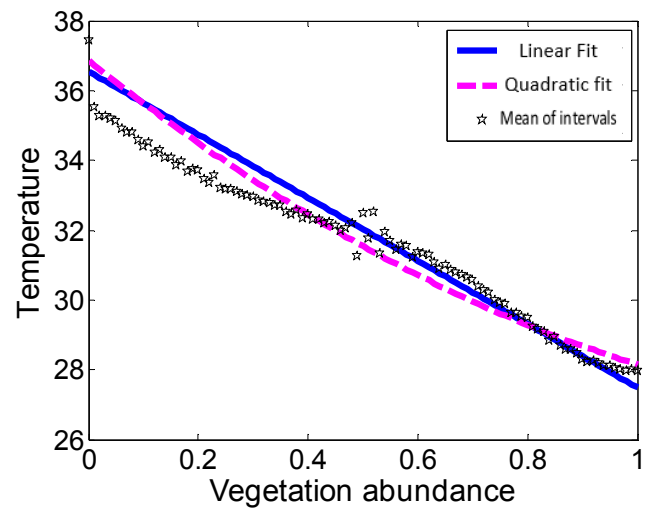

(a) Landsat TM, 7 September 1992

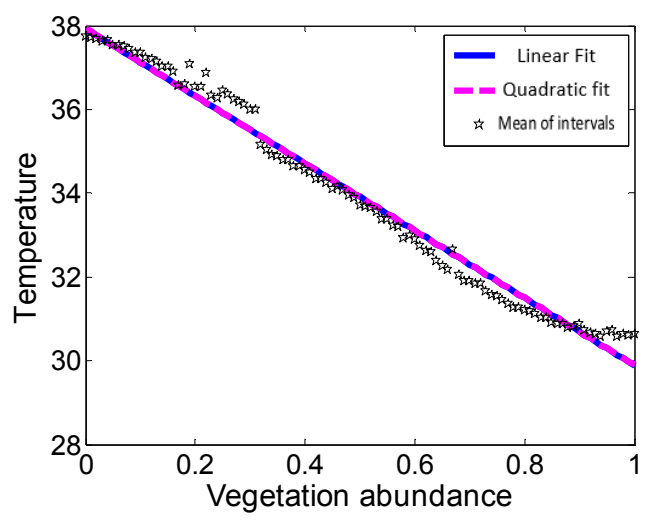

(c) Landsat ETM+, 1 July 1999

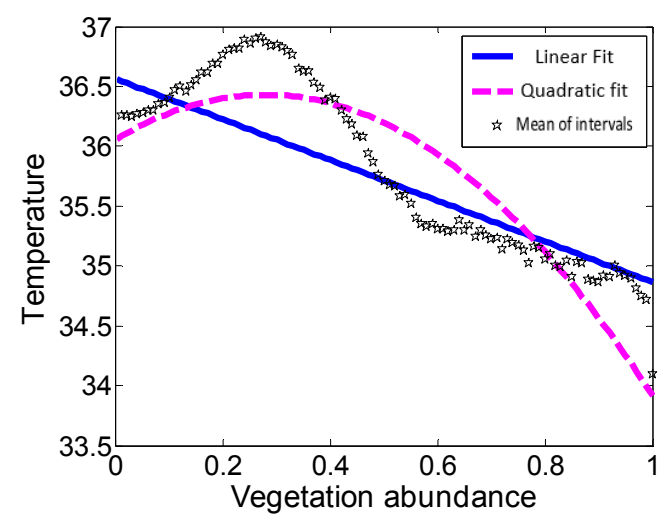

(e) Terra ASTER, 12 June 2004

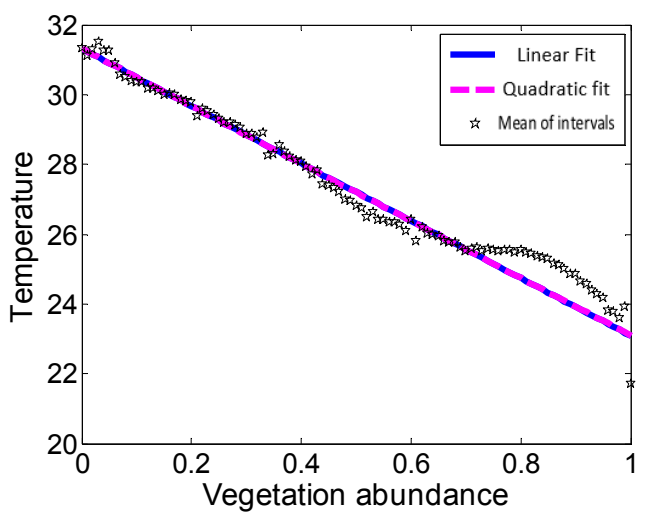

(b) Landsat TM, 21 September 1997

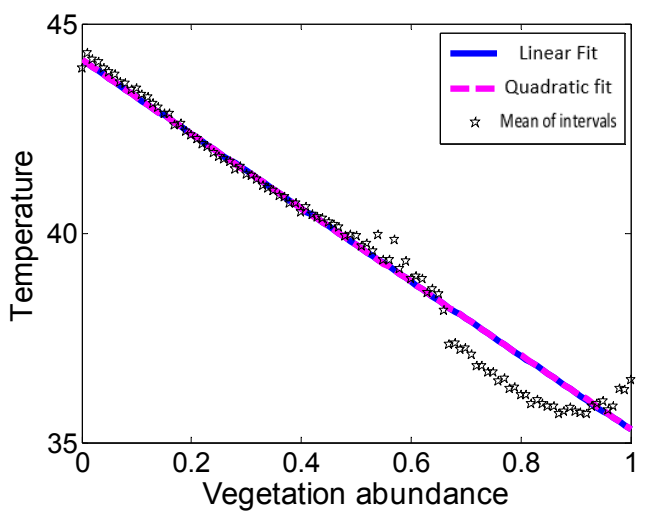

(d) Landsat ETM+, 19 May 2001

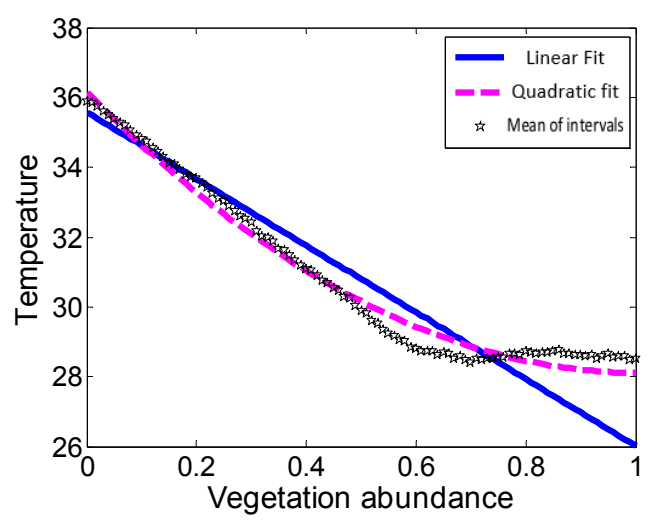

(f) Terra ASTER, 8 August 2007

Figure 11. Examples of relation between urban vegetation abundance and LST.

Compared to NDVI and LST, the correlation of UVA and LST is easier to discern. In the same way as for the analysis of NDVI-LST, the analysis will be divided into two parts:

(1). Directly based on analysis of all pixels, the value of UVA and LST are linearly fitted and quadratically fitted; Pearson's correlation coefficients are calculated for all pixel values (and presented in Table 3); 
(2). The range of UVA, [0,100\%], is divided into 100 intervals. The mean values of the 100 intervals and the corresponding mean values of LST are also linearly fitted; Pearson's correlation coefficients are calculated for the mean values (and presented in Table 3).

It warrants notice that the figure from Terra ASTER acquired on 12 June 2004 (Figure 11e) is different from the rest. In addition, the fit of LST and mean NDVI of each interval (NDVI $\in$ (Bare soil, Vegetation cover)) and Pearson's correlation coefficients (NDVI $\in($ Bare soil, Vegetation cover)) in Table 2, as well as Pearson's correlation coefficients (mean of intervals) in Table 3 show that the results from Terra ASTER acquired on 12 June 2004 are not as good as the rest. The image is as clear as the rest. In addition, the precipitation before the acquisition date (in Table 1) is similar to most of the rest. The image is clipped by the shape file of the study site, and the infrared band is resampled as the same resolution of visual near infrared band. One of the possible reasons is that the visual and near infrared band are not georeferenced well with thermal infrared band after these steps.

Based on the data presented in Figure 11 and Table 3, the negative correlation between LST and UVA is significant. Most of the results (except for that derived from Landsat TM, from 1992, portrayed in Figure 11) show that, to some extent, the trend of the correlation varies, while UVA reaches $60 \%$. Except for the result derived from Landsat ETM+ in 2001, other results show that the variation of LST with UVA decreases. The probable explanation is that increasing vegetation coverage is more effective in decreasing LST when the vegetation coverage is less than $60 \%$. Thus adding some trees to a denuded area will have a major effect on LST, but the benefits fall off as the area becomes more heavily vegetated. Most of the monomial coefficients are in the range of $[-9,-6]$, which reflects the numeric effect of vegetation in decreasing LST. Nevertheless, this is the average effect ignoring other conditions such as land surface moisture. The mean value of $R^{2}$ is 0.9448 , proving that the mean values of the intervals are close to having a negative linear correlation.

With respect to the polynomial fitting of pixel values, the results of the linear fitting and quadratic fitting are fairly similar. It is worth noting that the linear fitting curve almost coincides with the quadratic fitting curve with respect to Landsat TM data for 1997 and Landsat ETM+ data for 1999 and for 2001. The absolute values of the quadratic coefficient of the quadratic fitting are relatively small, but the values for $R^{2}$ are greater than that of the linear fitting, showing that the quadratic function is more capable of accurately representing the relationship.

For the pixel based analysis, the mean value of Pearson's correlation coefficients is -0.5078 , while it is -0.9716 for the mean of the intervals. This demonstrates that LST is influenced both by vegetation and other factors. Comparing the fitting for the mean values of the intervals and the polynomial fitting we can observe that:

(1). The monomial coefficients are approximate, with the mean values from 12 images being between -7.1116 and -7.3429 , which also show the numeric effect of vegetation in decreasing LST.

(2). The values of $R^{2}$ differ greatly. For the polynomial fitting for all 12 images, the mean values of $R^{2}$ are 0.2982 and 0.3055 . For the linear fitting and quadratic fitting, the values are much smaller than 0.9448 . This also demonstrates that LST is influenced by vegetation, whereas it is also influenced by other factors, including elevation mentioned above.

Comparing the correlation of NDVI-LST and UVA-LST, the Pearson's correlation coefficient of pixel values are -0.4880 and -0.5078 , respectively. The mean values derived from 12 images using the 
Pearson's correlation coefficient of the mean of the intervals are -0.9716 and -0.9559 , respectively. It is concluded from this that the correlation of UVA to LST is slightly more significant.

\subsection{Urban Forest Abundance and LST}

The scatter plot of the relationship between urban forest abundance (UFA) and LST in each year is displayed in Figure 12. It is an example derived from a Landsat ETM+ image from 1999. It is similar to UVA mentioned above. The range of UFA is [0,100\%]. In the following analysis, it is also divided into 100 intervals. The mean value of UFA in these intervals and the mean LST in the corresponding areas were collected, i.e., "mean of intervals", so that scatter plots of mean UFA and LST of the intervals is shown in Figure 13.

According to the scatter plots displayed in Figures 12 and 13, the relationship between UFA and LST is generally a negative correlation, but it is not as robust as the relation between UVA and LST.

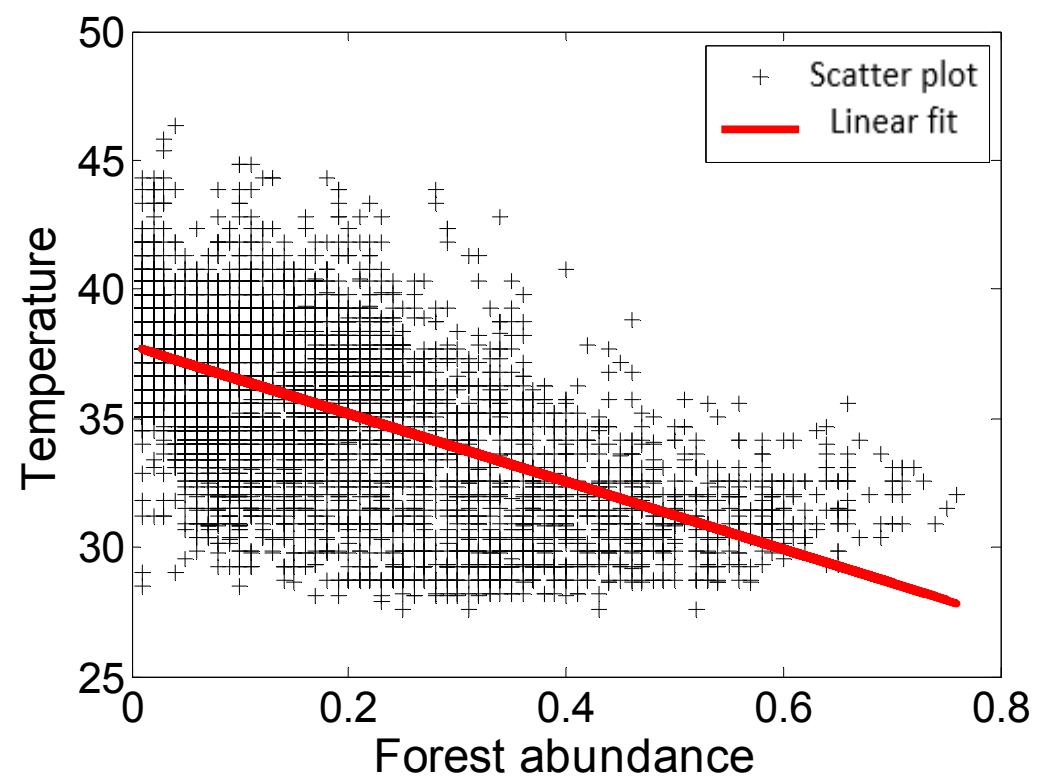

Figure 12. An example of scatter plot of UFA-LST (Landsat ETM+, 1 July 1999).

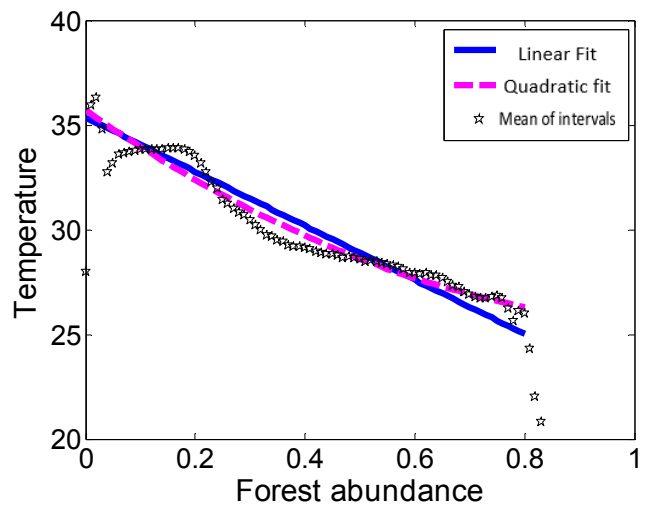

(a) Landsat TM, 13 May 1990

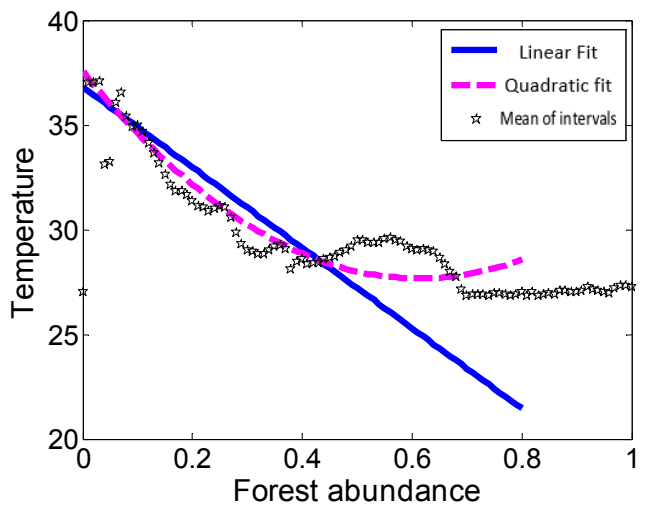

(b) Landsat TM, 8 May 1994

Figure 13. Cont. 


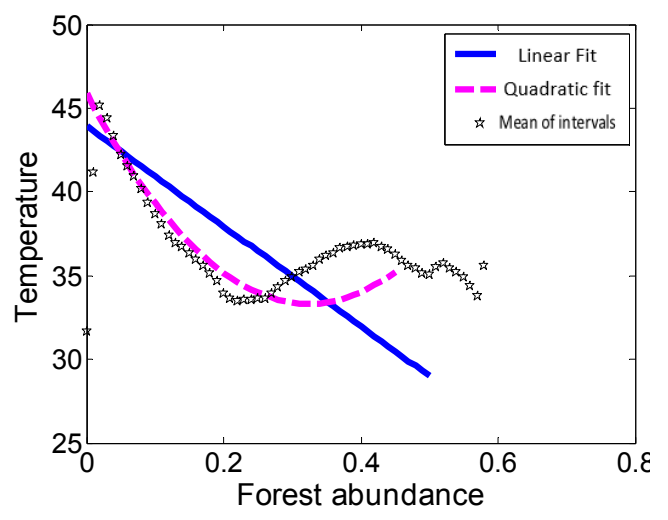

(c) Landsat TM, 6 May 1999

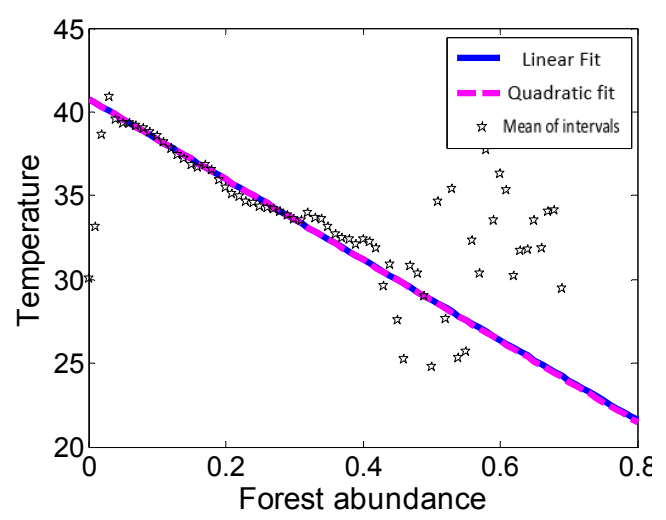

(e) Terra ASTER, 4 June 2001

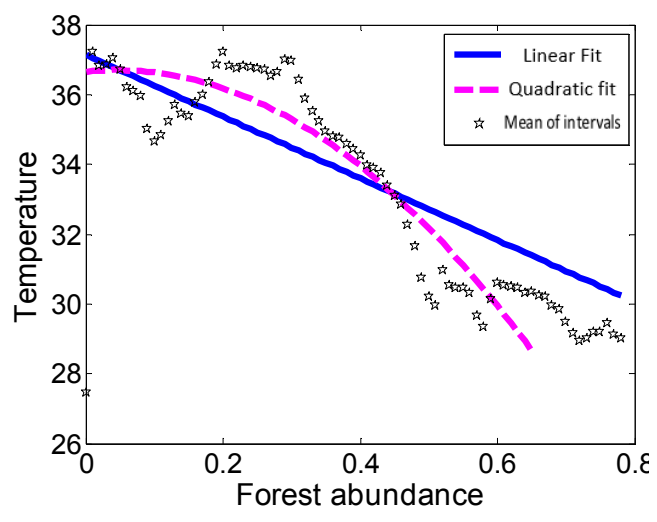

(d) Landsat ETM+, 30 April 2000

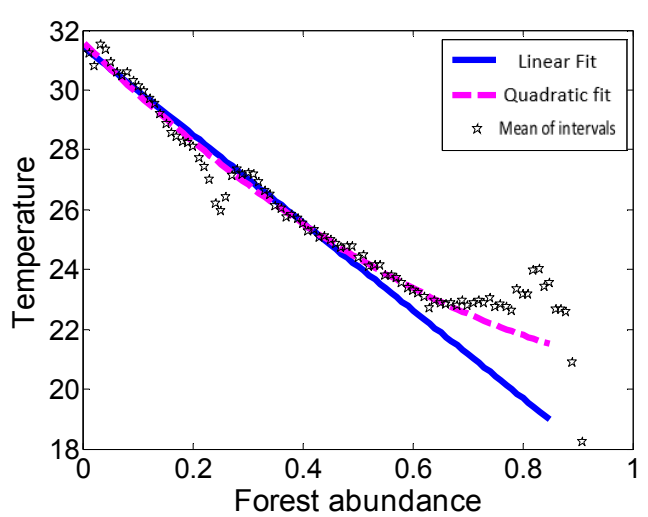

(f) Terra ASTER, 22 April 2006

Figure 13. Examples of relationships between urban forest abundance and LST.

Compared to UVA and LST, the correlation of UFA and LST is less apparent. It is similar to the analysis of NDVI-LST and UFA-LST, the analysis can also be divided into two parts:

(1). Based on analysis of all pixels, the values of UFA and LST are linearly fitted and quadratically fitted. Pearson's correlation coefficients are calculated for all pixel values (Table 4);

(2). The range of UFA, [0,100\%], is divided into 100 intervals. The mean values of the 100 intervals and the corresponding mean values of LST are also linearly fitted. Pearson's correlation coefficients are calculated for the mean values (Table 4).

Based on the analysis of Figure 13 and the values listed in Table 4, it is concluded that from fitting the mean values of the intervals, UFA and LST are generally in a negative correlation. Some of the scatter plots undulate as UFA increases, thus the correlation between UFA is more complicated and random than that of UVA and LST. The most probable explanations for this observation are that:

- There is not very much urban forest in the study area;

- Some western areas are mountainous areas covered with forest. So elements other that the UFA, e.g., elevation, soil moisture, also influence LST.

- $\quad$ In the study area, there are various types of trees, which play different roles in decreasing LST;

- $\quad$ There exist some errors in the calculation of UFA; 
The mean value of the monomial coefficients derived from the 12 images is -10.4548 . The absolute value is greater than that of the fitting of the means of the intervals of UVA and LST. This implies that forest is more successful in decreasing LST than other types of vegetation.

The mean value of $R^{2}$ is 0.6572 is lower than that derived from fitting the mean of the intervals of UVA and LST (0.9448). From this result, one can infer that the correlation between UFA and LST is more complicated than that between UVA and LST.

Since the correlation of UFA and LST varies depending on the type of remote sensing imagery employed in the analysis, these values are fitted utilizing the simplest means available, i.e., use of a linear fitting and quadratic fitting (see Figure 13). From the polynomial fitting of pixel values using the linear fitting with monomial coefficients, one obtains a mean value of -15.3428 , and these exhibit a larger difference. Its absolute value is also larger than that from fitting UVA and LST; the value of $R^{2}$ is barely 0.3452. Therefore, one can conclude that the result from the linear fitting is merely useful for reference.

In the quadratic fitting: the value of $R^{2}$ is 0.3452 , this is a bit higher than that from the linear fitting. From the use of Pearson's correlation coefficients one can conclude, for the calculation of the mean of the intervals, the mean value of Pearson's correlation coefficients is -0.7994 , this is lower than that of UVA-LST.

For the calculation of pixel values, the mean value of Pearson's correlation coefficients is -0.5439 . The absolute value is a bit greater than that of UVA-LST (which was -0.5078). It is noticed that this differs from other results: comparing the $R^{2}$ and absolute value of Pearson's correlation coefficients of the mean of the intervals, the results of UVA-LST are all lower than that of UFA-LST, except for the result discussed in this paragraph.

\subsection{Scale Effects}

The correlation of NDVI-LST, UVA-LST varies as a function of image resolution. Pixels in remote sensing imagery aggregate as the resolution decreases. In order to learn effects of the scale on the relationship between vegetation information and LST, GIS generated maps derived from remote sensing imagery of NDVI, UVA, UFA and LST are resampled to the resolution of $30 \mathrm{~m}, 60 \mathrm{~m}, 120 \mathrm{~m}, 240 \mathrm{~m}$, $480 \mathrm{~m}$ and $960 \mathrm{~m}$, and then the correlations are calculated separately (see Table 5).

In this scale-effect analysis, Landsat TM imagery from 1990, Landsat ETM+ from 2001 and Terra ASTER imagery from 2007 were chosen for sample calculations. The image used in this analysis range from the year 1990 to 2007 (listed in Table 1), and the images use in scale effects analysis were acquired in the beginning, the middle or the end of the range. They are each taken from a different type of sensor system, so that they are representative of a range of sensors, dates and resolutions.

\subsubsection{NDVI-LST}

In Section 3.1, NDVI was divided into four ranges to study its relation with LST. In this portion of the paper, only the range (bare soil, vegetation cover) is chosen for analysis of vegetation information used in the linear fitting while all pixels are involved in the calculation of Pearson's correlation coefficient.

In the case of Landsat TM from 1990 as the pixel size increased from $30 \mathrm{~m}$ to $960 \mathrm{~m}$, and the resolution decreased, the absolute value of the monomial coefficient decreases accordingly; $R^{2}$ and the absolute value of Pearson's correlation coefficient also decrease. This indicates that the relationship decreases as there is an increase of scale. 
In the case of Landsat ETM+ from 2001, some of the results are different from that of Landsat TM from 1990. As the pixel size increases from $30 \mathrm{~m}$ to $960 \mathrm{~m}$, and the resolution decreases, the absolute value of the monomial coefficient slightly decreases, but it is maintained at a high level, and it is in the range [14.84, 17.63]. It peaks when the resolution is $120 \mathrm{~m}$. The trend of $R^{2}$ reflects a similar effect.

In the case of Terra ASTER imagery from 2007, the results are similar to that for Landsat ETM from 200. The result of Landsat ETM+ from 2001 and Terra ASTER from 2007 are consistent with the analysis of Weng [9]. One of the possible reasons for the difference in the result of the analysis of Landsat TM from 1990, is that for the Pearson's correlation coefficient for all pixel values, the trend is different from above analysis. It increases as the scale increases, i.e., the pixel size increases. In the case of Landsat ETM+ from 2001 and Terra ASTER from 2007, it turns out to be positive, when the pixel size is greater than $120 \mathrm{~m}$, and reaches 0.83 , and 0.77 when the pixel size is $960 \mathrm{~m}$. In the case of Landsat TM from 1990, it is also positive while the pixel size is $960 \mathrm{~m}$. This indicates that the character of the NDVI-LST relationship might reverse as the pixel size increases.

\subsubsection{UVA-LST}

Table 5 shows that the scale effects of the UVA-LST relationship is quite different from that of the NDVI-LST relationship. As the resolution decreases and pixel size increases (from $30 \mathrm{~m}$ to $960 \mathrm{~m}$ ), the absolute value of the monomial coefficient of the linear fitting increases and then decreases, peaking when the pixel size is $120 \mathrm{~m}$ for Landsat TM from 1990 and Terra ASTER from 2007, and at a resolution of $90 \mathrm{~m}$ for Landsat ETM+ from 2001. The $R^{2}$ value as well as the absolute value of Pearson's correlation coefficients, generally decreases as the scale increases. When the pixel size enlarges to a maximum of $480 \mathrm{~m}$, they are tiny or even close to 0 , indicating that UFA and LST are not correlated.

\subsubsection{UFA-LST}

The analysis on the scale effects of the UFA-LST correlation is similar to that for the correlation between UFA and LST. The result is similar to that of the relationship between UVA and LST, and is different from that of the relationship between NDVI and LST. As the resolution decreases and pixel size increases (from $30 \mathrm{~m}$ to $960 \mathrm{~m}$ ), the absolute value of the monomial coefficient of the linear fitting increases and then decreases, peaking when the pixel size is $120 \mathrm{~m}$ for Landsat TM from 1990, and $90 \mathrm{~m}$ for Landsat ETM+ from 2001 and Terra ASTER from 2007. Similar to the result for the relationship between UVA and LST, the $R^{2}$ value, as well as the absolute value of Pearson's correlation coefficients, generally decreases as the scale increases. When the pixel size enlarges to a maximum of $480 \mathrm{~m}$, they are tiny or even close to 0 , indicating that UFA and LST are not correlated.

\subsubsection{Summary}

The resolution scale has an influence on the correlation between vegetation information and LST. For UVA-LST and UFA-LST, the $R^{2}$ and Pearson's correlation coefficient peaks at a resolution around $120 \mathrm{~m}$, and decreases to near 0 at $960 \mathrm{~m}$, this indicates that the correlation is most significant at a observed scale around $120 \mathrm{~m}$ (Table 5). 
Table 2. Coupling relationship between normalized difference vegetation index (NDVI) and land surface temperature (LST).

\begin{tabular}{|c|c|c|c|c|c|c|c|c|c|c|c|}
\hline & \multicolumn{3}{|c|}{ Thresholds of NDVI } & \multicolumn{3}{|c|}{$\begin{array}{c}\text { Fit of LST and NDVI } \\
\text { NDVI } \in \text { (Bare soil, Vegetation cover) }\end{array}$} & \multicolumn{3}{|c|}{$\begin{array}{c}\text { Fit of LST and mean NDVI of each interval } \\
\text { NDVI } \in \text { (Bare soil, Vegetation cover) }\end{array}$} & \multicolumn{2}{|c|}{ Pearson's correlation coefficients } \\
\hline & Water & Bare Soil & $\begin{array}{l}\text { Vegetation } \\
\text { Cover }\end{array}$ & $\begin{array}{l}\text { Monomial } \\
\text { coefficient }\end{array}$ & Constant & $R^{2}$ & $\begin{array}{l}\text { Monomial } \\
\text { coefficient }\end{array}$ & Constant & $R^{2}$ & All Pixels & $\begin{array}{c}\text { NDVI } \in \text { (Bare soil, } \\
\text { Vegetation cover })\end{array}$ \\
\hline 1990 TM & -0.45 & -0.09 & 0.56 & -12.2928 & 35.4764 & 0.3408 & -12.4806 & 35.5156 & 0.9867 & -0.6158 & -0.9934 \\
\hline 1992 TM & -0.2 & -0.05 & 0.58 & -17.9615 & 37.7120 & 0.6989 & -17.9276 & 37.7203 & 0.9790 & -0.8264 & -0.9894 \\
\hline 1994 TM & -0.32 & -0.1 & 0.42 & -14.7138 & 35.2906 & 0.2798 & -14.8015 & 35.2758 & 0.9951 & -0.4987 & -0.9976 \\
\hline 1997 TM & -0.8 & -0.15 & 0.74 & -7.9520 & 30.9888 & 0.3002 & -8.0716 & 31.0836 & 0.9491 & -0.5943 & -0.9742 \\
\hline 1999 TM & -0.7 & -0.05 & 0.78 & -13.7330 & 43.7044 & 0.3765 & -15.5863 & 44.3581 & 0.9313 & -0.5070 & -0.9650 \\
\hline 1999 ЕТМ+ & -0.3 & -0.14 & 0.34 & -18.6408 & 36.1800 & 0.5177 & -18.2092 & 36.1230 & 0.9812 & -0.7058 & -0.9906 \\
\hline 2000 ETM+ & -0.8 & -0.33 & 0.32 & -12.2349 & 33.5019 & 0.2319 & -14.3637 & 33.3297 & 0.9702 & -0.3212 & -0.9850 \\
\hline 2001 ETM+ & -0.58 & -0.32 & 0.2 & -17.1152 & 38.9377 & 0.3141 & -17.2958 & 38.9225 & 0.9902 & -0.4912 & -0.9951 \\
\hline 2001 ASTER & -0.5 & -0.08 & 0.42 & -24.0389 & 38.5407 & 0.1771 & -25.6857 & 38.5730 & 0.9748 & -0.3923 & -0.9873 \\
\hline 2004 ASTER & -0.23 & -0.09 & 0.5 & -18.0121 & 35.2307 & 0.0566 & -11.8544 & 35.2114 & 0.4391 & -0.1333 & -0.6626 \\
\hline 2006 ASTER & -0.2 & -0.09 & 0.45 & -12.6498 & 29.7159 & 0.0347 & -11.3023 & 29.8595 & 0.8687 & -0.1394 & -0.9320 \\
\hline 2007 ASTER & -0.5 & -0.09 & 0.34 & -21.6386 & 35.4286 & 0.3402 & -21.1473 & 35.3610 & 0.9966 & -0.6307 & -0.9983 \\
\hline Mean & -0.47 & -0.13 & 0.47 & -15.9153 & 35.8923 & 0.3057 & -15.7272 & 35.9445 & 0.9218 & -0.4880 & -0.9559 \\
\hline
\end{tabular}


Table 3. Coupling relationship between vegetation and LST.

\begin{tabular}{|c|c|c|c|c|c|c|c|c|c|c|c|c|}
\hline & \multicolumn{3}{|c|}{ Fit of mean of intervals } & \multicolumn{3}{|c|}{ Linear fit } & \multicolumn{4}{|c|}{ Quadratic fit } & \multicolumn{2}{|c|}{ Pearson's correlation coefficients } \\
\hline & $\begin{array}{l}\text { Monomial } \\
\text { coefficient }\end{array}$ & Constant & $R^{2}$ & $\begin{array}{l}\text { Monomial } \\
\text { coefficient }\end{array}$ & Constant & $R^{2}$ & $\begin{array}{l}\text { Quadratic } \\
\text { coefficient }\end{array}$ & $\begin{array}{l}\text { Monomial } \\
\text { coefficient }\end{array}$ & Constant & $R^{2}$ & Pixel value & Mean of intervals \\
\hline 1990 TM & -8.0942 & 35.6088 & 0.9781 & -8.1612 & 35.5866 & 0.4100 & -1.3365 & -7.0286 & 35.4868 & 0.4109 & -0.6403 & -0.9890 \\
\hline 1992 ТМ & -7.4503 & 35.4107 & 0.9744 & -9.0569 & 36.5539 & 0.6626 & 3.8315 & -12.5202 & 36.8455 & 0.6698 & -0.8140 & -0.9871 \\
\hline 1994 TM & -6.7556 & 36.4812 & 0.9936 & -6.5170 & 36.3318 & 0.2760 & -1.5332 & -5.2720 & 36.2340 & 0.2772 & -0.5253 & -0.9968 \\
\hline 1997 TM & -7.5678 & 31.1136 & 0.9717 & -8.2169 & 31.3132 & 0.4133 & 0.0570 & -8.2664 & 31.3178 & 0.4133 & -0.6429 & -0.9858 \\
\hline 1999 ТМ & -12.2816 & 44.9093 & 0.9340 & -10.2816 & 43.8315 & 0.3177 & -9.4809 & -2.6838 & 43.2458 & 0.3382 & -0.5637 & -0.9665 \\
\hline 1999 ЕТМ+ & -8.2592 & 38.0257 & 0.9845 & -8.0378 & 37.9278 & 0.5256 & 0.0362 & -8.0676 & 37.9303 & 0.5256 & -0.7250 & -0.9922 \\
\hline 2000 ETM+ & -8.4197 & 38.0622 & 0.9466 & -6.0629 & 37.0959 & 0.1504 & -7.5576 & -0.6721 & 36.7461 & 0.1701 & -0.3878 & -0.9730 \\
\hline 2001 ЕTM+ & -9.3462 & 44.2796 & 0.9772 & -8.8133 & 44.1252 & 0.2892 & 0.0476 & -8.8476 & 44.1275 & 0.2892 & -0.5378 & -0.9885 \\
\hline 2001 ASTER & -6.7738 & 40.2789 & 0.9854 & -6.0567 & 39.8884 & 0.1332 & -4.9580 & -1.9717 & 39.4737 & 0.1409 & -0.3650 & -0.9927 \\
\hline 2004 ASTER & -2.2155 & 36.9150 & 0.7868 & -1.6963 & 36.5617 & 0.0199 & -4.8204 & 2.6790 & 36.0580 & 0.0339 & -0.1409 & -0.8870 \\
\hline 2006 ASTER & -2.9451 & 30.6702 & 0.9169 & -2.8875 & 30.6096 & 0.0236 & -0.8655 & -2.2508 & 30.5558 & 0.0238 & -0.1536 & -0.9576 \\
\hline 2007 ASTER & -8.0054 & 34.8716 & 0.8888 & -9.5506 & 35.5724 & 0.3568 & 7.8842 & -15.9222 & 36.1484 & 0.3725 & -0.5973 & -0.9427 \\
\hline Mean & -7.3429 & 37.2189 & 0.9448 & -7.1116 & 37.1165 & 0.2982 & -1.5580 & -5.9020 & 37.0141 & 0.3055 & -0.5078 & -0.9716 \\
\hline
\end{tabular}


Table 4. Coupling relationship between urban forest and LST.

\begin{tabular}{|c|c|c|c|c|c|c|c|c|c|c|c|c|}
\hline & \multicolumn{3}{|c|}{ Fit of mean of intervals } & \multicolumn{3}{|c|}{ Linear fit } & \multicolumn{4}{|c|}{ Quadratic fit } & \multicolumn{2}{|c|}{ Pearson's correlation coefficients } \\
\hline & $\begin{array}{l}\text { Monomial } \\
\text { coefficient }\end{array}$ & Constant & $R^{2}$ & $\begin{array}{l}\text { Monomial } \\
\text { coefficient }\end{array}$ & Constant & $R^{2}$ & $\begin{array}{l}\text { Quadratic } \\
\text { coefficient }\end{array}$ & $\begin{array}{l}\text { Monomial } \\
\text { coefficient }\end{array}$ & Constant & $R^{2}$ & $\begin{array}{l}\text { Pixel } \\
\text { value }\end{array}$ & Mean of intervals \\
\hline 1990 TM & -11.6010 & 34.5226 & 0.8539 & -12.9336 & 35.3560 & 0.4494 & 8.0636 & -18.1931 & 35.6938 & 0.4563 & -0.6704 & -0.9241 \\
\hline 1992 ТМ & -11.1884 & 36.4250 & 0.9112 & -11.5014 & 36.5410 & 0.6489 & 9.1876 & -18.6565 & 37.1977 & 0.6595 & -0.8055 & -0.9546 \\
\hline 1994 TM & -7.7636 & 33.3574 & 0.7008 & -19.1950 & 36.8026 & 0.4248 & 26.3016 & -32.2491 & 37.5484 & 0.4611 & -0.6517 & -0.8372 \\
\hline 1997 TM & -7.4677 & 27.6790 & 0.7026 & -13.8285 & 30.1439 & 0.3583 & 21.9188 & -29.4157 & 31.1497 & 0.4271 & -0.5986 & -0.8382 \\
\hline 1999 TM & -8.1828 & 38.8291 & 0.2550 & -29.8147 & 43.9045 & 0.3698 & 119.6103 & -77.4715 & 45.8674 & 0.4924 & -0.6081 & -0.5049 \\
\hline 1999 ЕТМ+ & -7.6300 & 36.2626 & 0.7260 & -12.8932 & 37.7325 & 0.3424 & 8.6190 & -17.2400 & 38.0232 & 0.3475 & -0.5851 & -0.8520 \\
\hline 2000 ETM+ & -11.0101 & 37.5955 & 0.7022 & -8.8423 & 37.1371 & 0.1636 & -22.1424 & 2.1104 & 36.6507 & 0.1895 & -0.4044 & -0.8379 \\
\hline 2001 ETM+ & -5.4096 & 41.3349 & 0.6384 & -9.9076 & 43.6218 & 0.2384 & 15.5237 & -21.7775 & 44.2037 & 0.2963 & -0.4882 & -0.7990 \\
\hline 2001 ASTER & -11.3096 & 37.6455 & 0.3905 & -23.9683 & 40.7667 & 0.1445 & -0.3147 & -23.8586 & 40.7600 & 0.1445 & -0.3801 & -0.6249 \\
\hline 2004 ASTER & -10.1165 & 36.0246 & 0.3953 & -12.9336 & 37.4387 & 0.0859 & -18.5385 & -5.1195 & 36.9165 & 0.0901 & -0.2931 & -0.6287 \\
\hline 2006 ASTER & -10.3612 & 30.2757 & 0.9011 & -14.6337 & 31.4104 & 0.1888 & 7.2639 & -18.0127 & 31.5644 & 0.1908 & -0.4345 & -0.9493 \\
\hline 2007 ASTER & -23.4166 & 38.5703 & 0.7096 & -13.6613 & 36.4287 & 0.3683 & 18.8188 & -25.2949 & 37.4774 & 0.3874 & -0.6069 & -0.8424 \\
\hline Mean & -10.4548 & 35.7102 & 0.6572 & -15.3428 & 37.2737 & 0.3152 & 16.1926 & -23.7649 & 37.7544 & 0.3452 & -0.5439 & -0.7994 \\
\hline
\end{tabular}


Table 5. Scale effect of the coupling relationships between vegetation information and LST.

\begin{tabular}{|c|c|c|c|c|c|c|c|c|c|c|}
\hline & \multirow[b]{2}{*}{ Resolution } & \multicolumn{3}{|c|}{13 May 1990, Landsat TM } & \multicolumn{3}{|c|}{19 May 2001, Landsat ETM+ } & \multicolumn{3}{|c|}{8 August 2007, ASTER } \\
\hline & & $\begin{array}{c}\text { Linear Fit, } \\
\text { Monomial } \\
\text { coefficient }\end{array}$ & $\begin{array}{c}\text { Linear Fit, } \\
R^{2}\end{array}$ & $\begin{array}{l}\text { Pearson's } \\
\text { correlation } \\
\text { coefficients }\end{array}$ & $\begin{array}{c}\text { Linear Fit, } \\
\text { Monomial } \\
\text { coefficient }\end{array}$ & $\begin{array}{c}\text { Linear Fit, } \\
R^{2}\end{array}$ & $\begin{array}{l}\text { Pearson's } \\
\text { correlation } \\
\text { coefficients }\end{array}$ & $\begin{array}{c}\text { Linear Fit, } \\
\text { Monomial } \\
\text { coefficient }\end{array}$ & $\begin{array}{c}\text { Linear Fit, } \\
R^{2}\end{array}$ & $\begin{array}{c}\text { Pearson's } \\
\text { correlation } \\
\text { coefficients }\end{array}$ \\
\hline \multirow{7}{*}{ 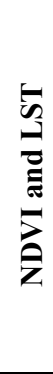 } & $30 \mathrm{M}$ & -12.29 & 0.34 & -0.62 & -17.12 & 0.31 & -0.49 & -21.64 & 0.34 & -0.63 \\
\hline & $60 M$ & -12.92 & 0.30 & -0.58 & -17.37 & 0.30 & -0.36 & -23.06 & 0.36 & -0.55 \\
\hline & $90 M$ & -13.25 & 0.25 & -0.54 & -17.55 & 0.31 & -0.18 & -23.65 & 0.38 & -0.39 \\
\hline & $120 M$ & -13.16 & 0.20 & -0.49 & -17.63 & 0.31 & -0.02 & -24.15 & 0.39 & -0.26 \\
\hline & $240 M$ & -11.57 & 0.09 & -0.32 & -16.96 & 0.28 & 0.37 & -24.11 & 0.39 & 0.16 \\
\hline & $480 \mathrm{M}$ & -5.95 & 0.01 & -0.12 & -15.92 & 0.24 & 0.66 & -22.74 & 0.38 & 0.55 \\
\hline & $960 M$ & 6.89 & 0.01 & 0.09 & -14.87 & 0.23 & 0.83 & -20.38 & 0.33 & 0.77 \\
\hline \multirow{7}{*}{ 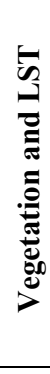 } & $30 \mathrm{M}$ & -8.16 & 0.41 & -0.64 & -8.81 & 0.29 & -0.54 & -9.55 & 0.36 & -0.60 \\
\hline & $60 \mathrm{M}$ & -8.35 & 0.35 & -0.59 & -8.99 & 0.23 & -0.48 & -10.14 & 0.37 & -0.61 \\
\hline & $90 \mathrm{M}$ & -8.62 & 0.29 & -0.54 & -8.84 & 0.17 & -0.41 & -10.40 & 0.33 & -0.57 \\
\hline & $120 \mathrm{M}$ & -8.64 & 0.24 & -0.49 & -8.56 & 0.12 & -0.35 & -10.50 & 0.29 & -0.54 \\
\hline & $240 M$ & -7.53 & 0.10 & -0.32 & -6.79 & 0.04 & -0.20 & -9.57 & 0.16 & -0.40 \\
\hline & $480 \mathrm{M}$ & -3.35 & 0.01 & -0.10 & -2.12 & 0.00 & -0.04 & -6.19 & 0.04 & -0.19 \\
\hline & $960 \mathrm{M}$ & 6.53 & 0.02 & 0.13 & -6.36 & 0.04 & -0.19 & 1.11 & 0.00 & 0.02 \\
\hline \multirow{7}{*}{ 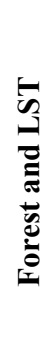 } & $30 \mathrm{M}$ & -12.93 & 0.45 & -0.67 & -9.91 & 0.24 & -0.49 & -13.66 & 0.37 & -0.61 \\
\hline & $60 \mathrm{M}$ & -14.01 & 0.42 & -0.65 & -10.86 & 0.22 & -0.47 & -14.58 & 0.33 & -0.58 \\
\hline & $90 M$ & -14.52 & 0.37 & -0.61 & -11.08 & 0.18 & -0.43 & -14.73 & 0.29 & -0.53 \\
\hline & $120 \mathrm{M}$ & -14.64 & 0.31 & -0.56 & -10.99 & 0.15 & -0.38 & -14.65 & 0.25 & -0.50 \\
\hline & $240 \mathrm{M}$ & -14.06 & 0.17 & -0.41 & -10.17 & 0.07 & -0.27 & -12.85 & 0.13 & -0.35 \\
\hline & $480 \mathrm{M}$ & -10.50 & 0.05 & -0.21 & -7.37 & 0.02 & -0.14 & -7.42 & 0.02 & -0.15 \\
\hline & $960 \mathrm{M}$ & 0.14 & 0.00 & 0.00 & -2.25 & 0.00 & -0.03 & 1.93 & 0.00 & 0.03 \\
\hline
\end{tabular}




\section{Conclusions}

Mounting land surface temperature has caused many problems, including the deterioration of the environment, amplified energy consumption, and growing mortality rates [7]. As Lo and Quattrochi pointed out, UHI is caused by dense buildings/roads with rare vegetation cover [37]. Obviously, UHI has been driven by a coupled human-environment system [3].This paper chooses Beijing, China as the case study area, and analyzes the coupling relationship between urban vegetation and land surface temperatures (LST) in detail. The coupling relationship between NDVI and LST is analyzed in detail based on the study of multiple years of data. It is postulated that the influence of NDVI on LST could be divided into four phases each subject to three thresholds. The threshold values are found to vary noticeably due to different external influences.

Based on the comparison of coupling relationships between NDVI, UVA, UFA and LST, the main conclusions are that NDVI, urban vegetation abundance (UVA) and urban forest abundance (UFA) are all negatively correlated with land surface temperature (LST). Urban vegetation and urban forest are both capable of decreasing LST. Urban forest has a more complex coupling relationship with LST but is the most effective factor in reducing LST. The negative correlation between urban vegetation information (NDVI, UVA, and UFA) and LST decreases as the scale increases; the influence of urban vegetation and urban forest increases initially and then decreases with pixel aggregation, which peaks in the range of $90 \mathrm{~m} \sim 120 \mathrm{~m}$ resolution. It is of significance to analyze the spatial pattern of high LST and its driving forces for policy implications.

The monomial coefficient of linear fit of UVA-LST and UFA-LST could be a quantitative reference for decision making on decreasing LST in hot summers. It is one of the proofs that urban forest provides much more services on adjusting land surface thermal environment than grassland or shrubs covering equivalent areas, so that urban forest is not only economic in land use especially in the crowded cities but also more capable in mitigating UHI. Future analysis would focus on the influence of detailed urban forest information on LST, such as urban forest structure and the surrounding land use of urban forest.

\section{Acknowledgments}

We would like to acknowledge the funding of Zhejiang Provincial Natural Science Foundation of China (Y1110925; Y5110343), the Natural Science Foundation of China (41430637; 41329001), and Chinese Ministry of Education (13JJD790008).

\section{Author Contributions}

Chudong Huang co-designed research, performed data analysis, and wrote the manuscript. Xinyue Ye co-designed research and extensively updated the manuscript.

\section{Conflicts of Interest}

The authors declare no conflict of interest. 


\section{References}

1. Dai, X.; Guo, Z.; Zhang, L.; Li, D. Spatiotemporal Exploratory Analysis of Urban Surface Temperature Field in Shanghai, China. Stoch. Environ. Res. Risk. Assess. 2010, 24, 247-257.

2. Wei, Y.; Ye, X. Beyond Convergence: Space, Scale, and Regional Inequality in China. J. Econ. Soc. Geogr. 2009, 100, 59-80.

3. Yue, W.; Liu, Y.; Fan, X.; Ye, P.; Wu, C. Assessing Spatial Pattern of Urban Thermal Environment in Shanghai, China. Stoch. Environ. Res. Risk. Assess. 2012, 26, 899-911.

4. Weng, Q. Thermal infrared remote sensing for urban climate and environmental studies: Methods, applications, and trends. ISPRS J. Photogramm 2009, 64, 335-344.

5. Yang, W.; Li, F.; Wang, R.; Hu, D. Ecological benefits assessment and spatial modeling of urban ecosystem for controlling urban sprawl in Eastern Beijing, China. Ecol. Complex. 2011, 81, 153-160.

6. Weng, Q.; Rajasekar, U.; Hu, X. Modeling urban heat islands and their relationship with impervious surface and vegetation abundance by using ASTER images. Geosci. Remote Sens. 2011, 49, 4080-4089.

7. Li, J.; Wang, X.; Wang, X.; Ma, W.; Zhang, H. Remote sensing evaluation of urban heat island and its spatial pattern of the Shanghai metropolitan area, China. Ecol. Complex. 2009, 6, 413-420.

8. Makoto, Y.; Robert, D.; Yoehitake, K. The cooling effect of paddy fields on summertime air temperature in residential Tokyo, Japan. Landsc. Urban Plan 2001, 53, 17-27.

9. Weng, Q.; Lu, D.; Schubring, J. Estimation of land surface temperature-vegetation abundance relationship for urban heat island studies. Remote Sens. Environ. 2004, 89, 467-483.

10. Xiao, R.; Weng, Q.; Ouyang, Z.; Li, W.; W.S.; Zhang, Z. Land Surface Temperature Variation and Major Factors in Beijing, China. Photogramm. Eng. Remote Sens. 2008, 74, 451-461.

11. Li, J.; Song, C.; Cao, L.; Zhu, F.; Meng, X.; Wu, J. Impacts of landscape structure on surface urban heat islands: A case study of Shanghai, China. Remote Sens. Environ. 2011, 115, 3249-3263.

12. Zhan, W.; Zhang, Y.; Ma, W.; Yu, Q.; Chen, L. Estimating influences of urbanizations on meteorology and air quality of a Central Business District in Shanghai, China. Stoch. Environ. Res. Risk. Assess. 2012, 26, 353-365.

13. Glenn, E.P.; Huete, A.R.; Nagler, P.L.; Nelson, S.G. Relationship between remotely-sensed vegetation indices, canopy attributes and plant physiological processes: what vegetation indices can and cannot tell us about the landscape. Sensors 2008, 8, 2136-2160.

14. Théau, J.; Sankey, T.T.; Weber, K.T. Multi-sensor analyses of vegetation indices in a semi-arid environment. GISci. Remote Sens. 2010, 47, 260-275.

15. Liu, Y.; Wang, X.; Guo, M.; Tani, H.; Matsuoka, N.; Matsumura, S. Spatial and Temporal Relationships among NDVI, Climate Factors, and Land Cover Changes in Northeast Asia from 1982 to 2009. GISci. Remote Sens. 2011, 48, 371-393.

16. Carlson, T.N.; Gillies, R.R.; Perry, E.M. A method to make use of thermal infrared temperature and NDVI measurements to infer surface soil water content and fractional vegetation cover. Remote Sens. Rev. 1994, 9, 161-173.

17. Roy, S.S.; Yuan, F. Patterns and variability of summer NDVI in response to climate variables in Minnesota. GISci. Remote Sens. 2007, 44, 166-181. 
18. Amiri, R.; Weng, Q.; Alimohammadi, A.; Alavipanah, S.K. The spatial-temporal dynamics of land surface temperatures in relation to fractional vegetation cover and land use/cover in the Tabriz urban area, Iran. Remote Sens. Environ. 2009, 113, 2606-2617.

19. Tian, P.; Tian, G.; Wang, F.; Wang, Y. Analyzing urban heat island effect and vegetation index relation using Landsat TM image. Bull. Sci. Technol. 2006, 22, 708-713.

20. Huang, C.; Chen, Q.; Ying, S.; Zhao, F.; Shao, Y.; Yu, W.; Chen, J.; Liu, F.; Xu, X.; Li, J. An Analysis on the Coupling Relationship between Urban Vegetation and Land Surface Temperature in Hangzhou Based on Aster Imagery. In Proceedings of the International Geoscience and Remote Sensing Symposium (IGARSS), Cape Town, South Africa, 13-17 July 2009.

21. Myint, S.W.; Brazel, A.; Okin, G.; Buyantuyev, A. Combined effects of impervious surface and vegetation cover on air temperature variations in a rapidly expanding desert city. GISci. Remote Sens. 2010, 47, 301-320.

22. Qin, Y.; Liu, K.; Wang, Y. Ecological functions of green land system in Xi'an. Chin. J. Ecol. 2006, $25,135-139$.

23. McPherson, E.G.; Nowak, D.; Heisler, G.; Grimmond, S.; Souch, C.; Grant, R.; Rowntree, R. Quantifying urban forest structure, function, and value: the Chicago Urban Forest Climate Project. Urban Ecosyst. 1997, 1, 49-61.

24. Huang, C.; Shao, Y.; Liu, J.; Chen, J. Temporal analysis of urban forest in Beijing using Landsat imagery. J. Appl. Remote Sens. 2007, 1, 013514.

25. Szantoi, Z.; Escobedo, F.; Wagner, J.; Rodriguez, J.M.; Smith, S. Socioeconomic Factors and Urban Tree Cover Policies in a Subtropical Urban Forest. GISci. Remote Sens. 2012, 49, 428-449.

26. Nowak, D.J.; Rowntree, R.A.; McPherson, E.G.; Sisinni, S.M.; Kerkmann, E.R.; Stevens, J.C. Measuring and analyzing urban tree cover. Landsc. Urban Plan. 1996, 36, 49-57.

27. Nowak, D.J.; Crane, D.E.; Stevens, J.C. Air pollution removal by urban trees and shrubs in the United States. Urban For. Urban Green. 2006, 4, 115-123.

28. Nowak, D.J.; Greenfield, E.J. Tree and impervious cover change in U.S. cities. Urban For. Urban Green. 2012, 11, 21-30.

29. Breshears, D.D.; Barnes, F.J. Interrelationships between plant functional types and soil moisture heterogeneity for semiarid landscapes within the grassland/forest continuum: A unified conceptual model. Landsc. Ecol. 1999, 14, 465-478.

30. Ha, W.; Gowda, P.H.; Howell, T.A. Downscaling of Land Surface Temperature Maps in the Texas High Plains with the TsHARP Method. GISci. Remote Sens. 2011, 48, 583-599.

31. Montandon, L.; Small, E. The impact of soil reflectance on the quantification of the green vegetation fraction from NDVI. Remote Sens. Environ. 2008, 112, 1835-1845.

32. Qin, Z.; Li, W.; Xu, B.; Chen, Z.; Liu, J. The Estimation of Land Surface Emissivity for Landsat TM6. Remote Sens. Land Resour. 2004, 3, 28-32.

33. Sobrino, J.; Jiménez-Muñoz, J.; Paolini, L. Land surface temperature retrieval from LANDSAT TM 5. Remote Sens. Environ. 2004, 90, 434-440.

34. Jiménez-Muñoz, J.; Sobrino, J. A Generalized Single-channel Method for Retrieving Land Surface Temperature from Remote Sensing Data. J. Geophys. Res. 2003, 108, 4688-4695.

35. Kaufman, Y.; Gao, B. Remote Sensing of Water Vapor in the Near IR from EOS/MODIS. Geosci. Remote 1992, 30, 871-884. 
36. Mao, K.; Tang, H.; Chen, Z.; Qiu, Y.; Qin, Z.; Li, M. A split-window algorithm for retrieving land-surface temperature from ASTER data. Remote Sens. Inform. 2006, 5, 7-11.

37. Lo, C.P.; Quattrochi, D.A. Land-Use and Land-cover Change, Urban Heat Island Phenomenon, and Health Implications. Photogramm. Eng. Remote Sens. 2003, 69, 1053-1063.

(C) 2015 by the authors; licensee MDPI, Basel, Switzerland. This article is an open access article distributed under the terms and conditions of the Creative Commons Attribution license (http://creativecommons.org/licenses/by/4.0/). 